\title{
A dissection of SARS-CoV2 with clinical implications (Review)
}

\author{
FELICIAN STANCIOIU ${ }^{1}$, GEORGIOS Z. PAPADAKIS ${ }^{2}$, STELIOS KTENIADAKIS ${ }^{3}$, \\ BORIS NIKOVAEVICH IZOTOV ${ }^{4}$, MICHAEL D. COLEMAN ${ }^{5}$, \\ DEMETRIOS A. SPANDIDOS ${ }^{6}$ and ARISTIDIS TSATSAKIS ${ }^{4,7}$ \\ ${ }^{1}$ Bio-Forum Foundation, 030121 Bucharest, Romania; ${ }^{2}$ Department of Radiology, Medical School, University of Crete, \\ 71003 Heraklion; ${ }^{3}$ Emergency Department, Venizeleion General Hospital, 71409 Heraklion, Greece; \\ ${ }^{4}$ Department of Analytical and Forensic Medical Toxicology, Sechenov University, 119991 Moscow, \\ Russia; ${ }^{5}$ School of Life and Health Sciences, Aston University, B4 7ET Birmingham, UK; \\ ${ }^{6}$ Laboratory of Clinical Virology, Medical School, ${ }^{7}$ Department of Forensic Sciences \\ and Toxicology, Faculty of Medicine, University of Crete, 71003 Heraklion, Greece
}

Received May 15, 2020; Accepted June 9, 2020

DOI: $10.3892 /$ ijmm.2020.4636

\begin{abstract}
We are being confronted with the most consequential pandemic since the Spanish flu of 1918-1920 to the extent that never before have 4 billion people quarantined simultaneously; to address this global challenge we bring to the forefront the options for medical treatment and summarize SARS-CoV2 structure and functions, immune responses and known treatments. Based on literature and our own experience we propose new interventions, including the use of amiodarone, simvastatin, pioglitazone and curcumin. In mild infections (sore throat, cough) we advocate prompt local treatment for the naso-pharynx (inhalations; aerosols; nebulizers); for moderate to severe infections we propose a tried-and-true treatment: the combination of arginine and ascorbate, administered orally or intravenously. The material is organized in three sections: i) Clinical aspects of COVID-19; acute respiratory distress syndrome (ARDS); known treatments; ii) Structure and functions of SARS-CoV2 and proposed antiviral drugs; iii) The combination of arginine-ascorbate.
\end{abstract}

\section{Contents}

1. Clinical aspects of COVID-19 infections; acute respiratory distress syndrome (ARDS); known and potential treatments

2. SARS-CoV2 molecules and proposed antiviral drugs

3. The combination of arginine-ascorbate

Correspondence to: Dr Felician Stancioiu, Bio-Forum Foundation, Splai Unirii Nr 8, Parter, 030121 Bucharest, Romania

E-mail: felicians@bio-forum.net

Key words: SARS-CoV2, COVID-19, antiviral treatment, ARDS, sepsis, arginine, ascorbate, coronavirus
1. Clinical aspects of COVID-19 infections; acute respiratory distress syndrome (ARDS); known and potential treatments

In China, the first comprehensive analysis published on the COVID-19 (1) included 44,672 cases and 1,023 deaths, with an overall case-fatality rate (CFR) of $2.3 \%$. There were 0 deaths in patients 9 years old or younger, and the CFR increased with advancing age (70-79 years: $8.0 \%, 80$ years and older: $14.8 \%$ ) and also with comorbid conditions: $5.6 \%$ for cancer, $6.0 \%$ for hypertension, $7.3 \%$ for diabetes, $10.5 \%$ for cardiovascular disease; for intensive care patients CFR was $49.0 \%$. Similar data were published by other authors on the China epidemic $(2,3)$; another analysis (4) identified 3 biological markers associated with the severity of the infection and progression to ARDS and death: i) neutrophilia; ii) increased lactate dehydrogenase LDH and iii) coagulation dysfunction (D-dimer). There were 2 unexpected findings: i) patients with fever $\geq 39^{\circ} \mathrm{C}$ were more likely to develop ARDS but also less likely to die; and ii) administering methylprednisolone to patients with ARDS was associated with lower risk of death.

In Europe there was a higher rate of severe cases in Italy $(5,6)$ where $12 \%$ of positive patients were admitted to ICU vs. $5 \%$ in China; this difference was attributed to a higher proportion of elderly and increased social contact $(7,8)$. Data from Germany (9) showed that $\sim 1 / 3$ of admitted patients had leucopenia and most of these (80\%) had lymphopenia; C-reactive protein (CRP) was often increased and very high CRPs were associated with a less favorable outcome for the patient. Approximately $40 \%$ of admitted patients had increased LDH, D-dimer and/or thrombocytopenia, and an $\mathrm{LDH}$ value of $>400 \mathrm{IU} / \mathrm{ml}$ was associated with more severe disease. Troponin was increased in a small number of patients, with unclear significance.

In the USA, a recent publication showed that a majority (71\%) of COVID-19 patients with ARDS and in intensive care, also had hypotension $(10,11)$. There is already an extensive clinical experience with ARDS in the USA, where $>180,000$ patients annually are admitted with this pathology and ARDS mortality 
has improved from 40 to $50 \% 10$ years ago to $20-25 \%$ in recent clinical trials. A group of USA intensive care specialists led by Dr Calfee has analyzed $>30$ biomarkers and clinical variables from two large clinical trials on ARDS (12); subsequently an ARDS patient population was identified which comprised $\sim 30 \%$ of total ARDS cases, had higher levels of IL-6 and IL-8, more patients with sepsis and in need for vasopressor treatment, with higher mortality but also responding better to high positive expiratory-end pressure (PEEP) therapy. With data from more clinical trials (13), two ARDS populations were identified, the hypoinflammatory and hyperinflammatory subphenotypes, with distinctive and opposite characteristics. The former has low levels of IL-6, IL-8, tumor necrosis factor receptor 1 (TNFr1), lower mortality as well as higher number of ventilator-free days, high bicarbonate and protein $C$; the latter has high levels of IL-6, IL-8, TNFr1, low levels of bicarbonate and protein $\mathrm{C}$, low number of ventilator-free days and higher mortality.

Treatment-wise, the same group showed that in the ARDS hyperinflammatory subphenotype better outcomes were obtained with administration of high PEEP, liberal fluid strategy (vs. conservative fluid administration) and simvastatin, while rosuvastatin administration was of no benefit (12,14-16); Table I summarizes the data from different clinical trials on ARDS subphenotypes. The observed difference between statins in ARDS may be explained by their solubility: while simvastatin is lipid-soluble, rosuvastatin is water-soluble, with important consequences on cell membrane interaction.

It is safe to say that COVID-19 patients who develop ARDS (with high levels of interleukins, low blood pressure) belong to the hyperinflammatory subphenotype and may benefit from the therapeutic insight associated with this group of patients (higher PEEP, liberal fluid strategy, and simvastatin). In critically-ill COVID-19 patients, increased LDH levels are likely associated with acidosis and if low blood pressure is also present, before vasopressors they are likely to benefit from administration of sodium bicarbonate (increments of $100 \mathrm{ml}$ of $8.4 \%$ solution).

Treatment-wise, after the SARS and MERS epidemics a few antivirals were proposed and tested and among these are mycophenolic acid, cyclosporine at low concentrations, chloroquine; chlorpromazine, loperamide, and lopinavir, found to be broad-spectrum coronavirus inhibitors (17). Recently FDA has approved remdesivir (GS5734 - an RNA polymerase inhibitor) as specific treatment for COVID-19; different protocols use chloroquine (500 mg q $12 \mathrm{~h}$ ); hydroxychloroquine (200 mg q 12 h); lopinavir/ritonavir (400/100 mg every $12 \mathrm{~h}$ ), $\alpha$-interferon (aerosol inhalation 5 million IUbid), and there are $>50$ treatments tested in clinical trials (18).

For ARDS, as the most severe form of COVID-19 infection, there is ample data from proteomics showing highly activated pathways of inflammation, increased levels of eosinophil- and neutrophil-derived proteins, epithelial and endothelial injury, matrix metalloproteinase 7 (MMP7), $\alpha$ - and $\beta$-hemoglobin, apolipoprotein A1, osteopontin and chemokines $(19,20)$. The context of increased inflammation in ARDS justifies the use of biological agents, antagonists of the IL-6 receptor (IL-6R), and TNF- $\alpha$, such as infliximab, rituximab, ustekinumab, etanercept, adalimumab and tocilizumab (18). However, the complexity of living biological systems with redundant pathways and dual-role modulators means that they do not always conform to mechanistic determinism, and this is especially true in patients with chronic diseases or co-morbid conditions, where modifications of physiological pathways translate into unknown but important factors with unexpected consequences. One such example is a clinical trial for sepsis which tested a recombinant IL-1 receptor antagonist (IL-1Ra) with negative results, but at the same time benefited patients with higher baseline levels of IL-1Ra (21).

Another important aspect is that multiple cellular pathways besides inflammation are simultaneously affected in ARDS, including coagulation, endothelial and epithelial injury pathways (apoptosis) and healing (fibrosis) in lungs. A unique molecular signature of lethal infection with another respiratory virus (PR8, an influenza virus) showed over-activation of pro-inflammatory pathways, NF- $\kappa \mathrm{B}$, IL-6, TNF and neutrophil chemotaxis (22), associated decreased activation of genes involved in lung homeostasis and repair. Neutrophils with high pro-inflammatory activity were numerous in lung infiltrates, their own chemokines further promoted neutrophil influx in a positive feedback loop; a dose-dependent survival was seen with partial neutrophil depletion in this type of lethal infection. Comparing viral replication in non-lethal vs. lethal infection they had similar viral replication rates, but the lethal infection had increased viral titers in the lungs, and also increased early pro-inflammatory neutrophil activation, resulting in pathologic neutrophil infiltration and fatal lung damage (23). Similar observations increased neutrophil- and neutrophil-attracting chemokines, delay in induction of IFN in airway epitlelial cells resulting in vascular leakage and lung damage were made in SARS and MERS suggesting a common pathogenical mechanism $(24,25)$. Indeed, the significant role of neutrophils in the promotion of ARDS-related alveolal damage was supported by a report in sepsis ARDS patients, where high neutrophil counts in bronchiolar lavage material harvested late in ARDS progression was associated with reduced patient survival (26). Hence, it has been proposed that the sulphone dapsone may show efficacy in COVID-19 related ARDS, as the drug is highly and rapidly effective at inhibiting cytokine-mediated neutrophil chemotaxis and respiratory burst in a variety of therapeutic contexts (27). Efficacy of Dapsone in the treatment of Pneumocystis pneumonia suggests it will penetrate the lung tissue sufficiently to attenuate neutrophil activity. The haemotoxicity of the drug can be ameliorated with concomitant cimetidine administration (27,28).

Overall, the major clinical manifestations: sore throat, cough, breathing difficulties, malaise, fever, chills, diarrhea, generalized myalgia, drowsiness, dyspnea, and pneumonia are similar in SARS-CoV2, MERS-CoV, and SARS CoV infections (29), but COVID-19 differentiates itself from MERS and SARS in infectivity (R0), with much higher human-to-human transmission rates owing much to the fact that infectivity is not restricted to symptomatic patients (30); however, we can improve therapeutic strategies with inferences from structural comparisons of these viruses.

\section{SARS-CoV2 molecules and proposed antiviral drugs}

SARS-CoV2 consists of two types of molecules: RNA and proteins; RNA encodes for 27 viral proteins, of which 16 are 
Table I. ARDS subphenotypes (data from Wilson and Calfee) (13).

Parameters

Hypoinflammatory

ARDS

Low
High
Low
High
Low

Conservative

administration of fluids

No

No
Hyperinflammatory ARDS

High

Low

High

Low

High

Liberal administration of fluids

Yes

No

Rosuvastatin administration has benefit on 90-day survival (HARP-2)

ARDS, acute respiratory distress.

non-structural proteins (nsps), and 11 are accessory and structural proteins. There are 4 major structural proteins: nucleocapsid protein $(\mathrm{N})$, spike surface glycoprotein $(\mathrm{S})$, matrix protein $(\mathrm{M})$, and small envelope protein $(\mathrm{E})$. The $N$-protein binds to viral RNA, encloses it in a capsid and assists RNA synthesis and folding during viral replication; it also modifies host responses, cell cycle and gene translation, and after RNA replication it guides the viral membrane proteins for viral assembly. The $S$-protein is essential for attachment and fusion of the virus to host cells (31).

Sequencing the SARS-CoV2 genome in February 2020 (32) showed that phylogenetically it belongs to the genus Betacoronavirus, subgenus Sarbecovirus, and has closer genetic similarity to SARS-CoV than MERS-CoV. The genome consists of a single, positive-stranded RNA with $\sim 30 \mathrm{k}(29,811)$ nucleotides; from these only 5 nucleotides were found to be different between SARS-CoV2 and SARS-CoV. Similar sequencing results (>99.9\% similarity) were obtained by different teams on different patient samples $(33,34)$ : GenBank sequences MN988668, NC_045512, MN938384.1, MN975262.1, MN985325.1 and MN994468.1.

Coronaviruses have the largest known RNA genomes and their RNA is transcribed via open reading frames (ORFs); this peculiarity increasing the efficacy of viral replication and mutagenesis, and making it more difficult to be eliminated by the immune system. The SARS-CoV2 genome has 14 ORFs of different lengths; first ORF has $\sim 10,000$ nucleotides $(\sim 2 / 3$ of viral RNA) and encodes nsps 1-16, with the structural and accessory proteins being translated from the remainder $1 / 3$ of RNA (35) (Fig. 1).

Comparing the amino acid sequence of SARS-CoV and SARS-CoV2 reveals identical sequences in the envelope, matrix, nsp7, nsp13 and accessory proteins p6 and 8b, while nsp3 and nsp2 had 102 and 61 amino acid substitutions, respectively.

Importantly, orf8 and orf10 are present in SARS-CoV2 but not in SARS-CoV (36). The orf8 protein from SARS-CoV2 has no known functional domain or motif and is different from the orf8 or orf $8 b$ of SARS-CoV, which does not have orf10 at all. However, ORF10 binds to heme and ORF8 to porphyrins (37); heme inactivation increases viral infectivity through inhibition of the host innate antiviral response (38) which relies on heme-containing enzymes such as nitric oxide synthase (detailed below); also increases viral permeation of tissues via porphirin binding and tissue destruction (39).

The spike (S) protein of the new virus contains 1,273 amino acids; compared to SARS-CoV it has 27 amino acid substitutions, 8 in the heptad repeat domain, 6 in the RBD, and 4 in the S1 subunit, modifying two peptides which are antigens for SARS-CoV (40). The binding energy between the viral $\mathrm{S}$ protein and host ACE2 receptor is higher in the new virus versus SARS-CoV $(-50.6 \mathrm{kcal} / \mathrm{mol}$ vs. $-78.6 \mathrm{kcal} / \mathrm{mol})$ suggesting a more stable bond (41); at the same time the affinity of the $S$ protein of the new virus for the ACE2 receptor is in the $15 \mathrm{nM}$ range, which is about 10-20 times higher than SARS-CoV, an important factor for the differential infectivity (42).

The $\mathrm{S}$ protein is a class I viral fusion protein like the influenza virus hemagglutinin (HA); SARS-CoV2 also has an $\mathrm{S} 1 / \mathrm{S} 2$ cleavage site which is recognizable by furin, a ubiquitous cell protease. When similar modifications (insertion of a polybasic furin cleavage site) occur in the hemagglutinin proteins of avian and human influenza viruses, their virulence is greatly increased (43).

Functionally the $\mathrm{S}$ protein has a receptor-binding subunit (S1), an $\mathrm{S} 2$ fusion domain (S2), separated by a cleavage site (S1/S2) and another cleavage site (S2') located within $\mathrm{S} 2$. The multiple cleavage sites are activated by a wide variety of proteases from the host cell: cathepsins, serine proteases from the trypsin-like transmembrane serine protease family (TTSP), and furin-like proprotein convertases.

Both SARS-CoV and SARS-CoV2 need S protein priming through cleavage by a host cellular protease (transmembrane protease serine 2 - TMPRSS2, TMPRSS11a, 


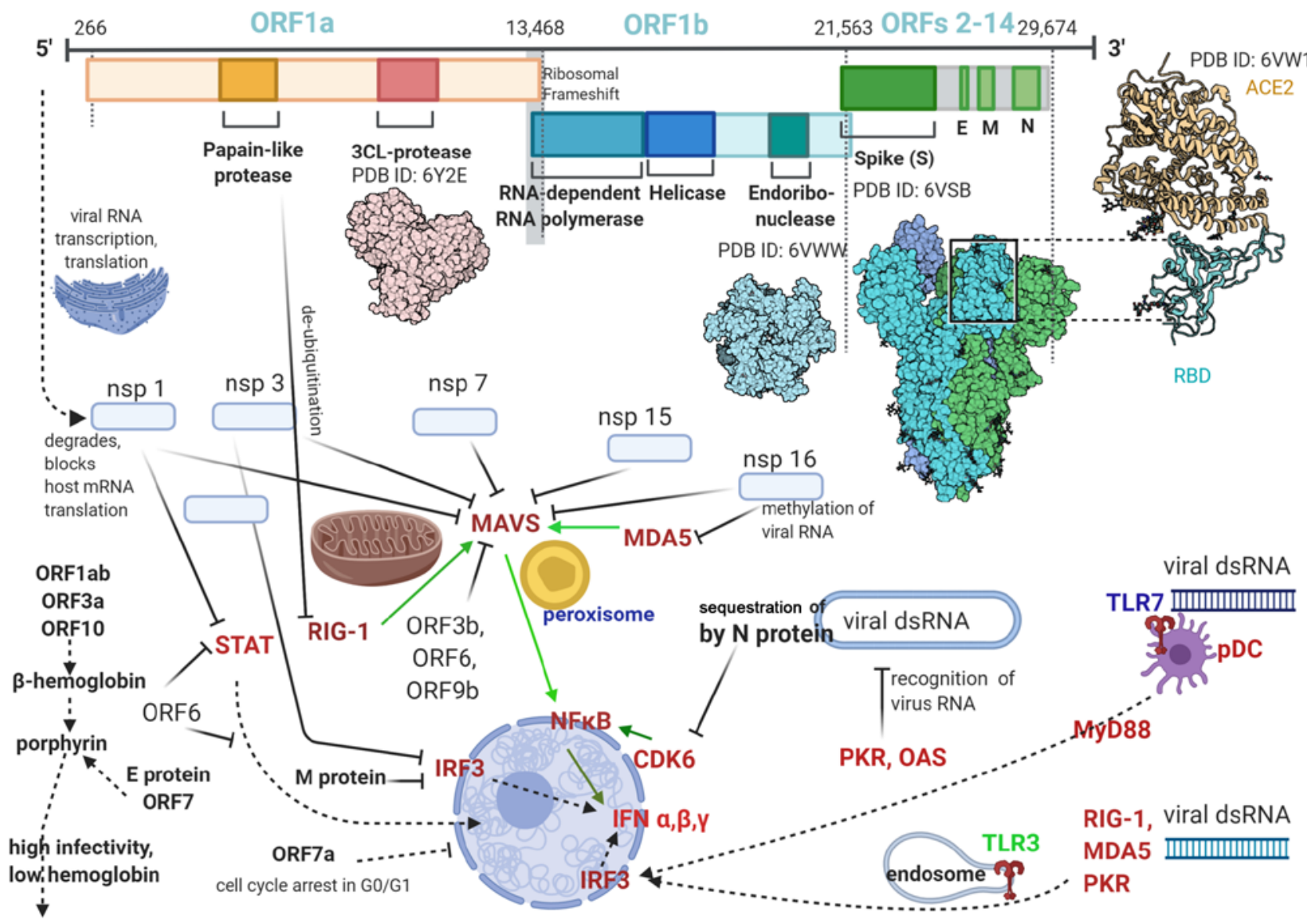

Figure 1. SARS-CoV2 genome, translated proteins and some of their known pro-viral actions.

hypoxanthine-aminopterin-thymidine, trypsin, elastase, cathepsin L) $(44,45)$, and the cell surface from respiratory epithelial cells has abundant TMPRSS2 and trypsin-like protease (46). Interestingly, human airway epithelial cells can be infected by SARS-CoV even when proteases from cell surface are absent (44), meaning that a cell fusion process used by SARS-CoV involves endosomal membranes and a treatment which blocks only the cell surface proteases or the endosomal protease will not prevent, but only depress viral cell entry; however, a combination of two substances, camostat and EST, a cathespsin inhibitor effectively blocked the viral entry into cells.

SARS-CoV2-infected cells aggregate to form syncytiums; the $\mathrm{S}$ protein of SARS-CoV2 can mediate a cell-cell syncytium formation without a proteolytic enzyme (trypsin), while SARS-CoV S protein cannot; thus the membrane fusion capacity of SARS-CoV2 is much higher than that of SARS-CoV (46).

The $\mathrm{S}$ protein of both coronaviruses has another peculiarity: its dependency on $\mathrm{Ca}^{2+}$ (47). Significant cell membrane ordering prior to membrane fusion is needed, and it requires the presence of $\mathrm{Ca}^{2+}$ ions because of the negatively charged residues in the fusion platform. Consequently the entry of SARS-CoV2 is highly dependent on the $\mathrm{Ca}^{2+}$ concentration in its cell environment, and calcium chelators inhibit viral fusion and cell entry. Thus it was observed that SARS-CoV entry is blocked by amiodarone, which blocks calcium channels in the endosome and lysosome (47).
The nsps perform essential functions in immune antagonism through formation of the viral replication complex and double membrane vesicles which shield the viral RNA, viral RNA proofreading, binding of nucleic acid and helicase activity (48).

Immunosuppressive functions of the SARS-CoV2 proteins. Besides needing to ensure the entry of viral material into cells and subsequent replication, the viral proteins and RNA also need to evade the host immune system, and because the success of viral infection depends on the impairment of the host antiviral response, this aspect deserves special attention.

Airway epithelial cells are able to prevent viral infections through multiple mechanisms. The airway surface liquid (ASL) is secreted by the submucosal glands, goblet and club cells and mobilized by cilium cells, and contains the gel-forming mucins MUC5B and MUC5AC, glycosaminoglycan keratin sulfate, and antimicrobial peptides and proteins (AMPs). ASL forms a pericilliary layer with volume, fluidity, $\mathrm{pH}$ and microbiome maintained in an optimal range for toxin elimination and the actions of AMPs, and facilitating mobilization of the innate immune response by macrophages, monocytes, dendritic cells, innate lymphoid cells, and $\gamma / \delta$ T cells. Finally an adaptive, specific immune response is triggered in response to antigens involving $\mathrm{T}$ and $\mathrm{B}$ lymphocytes, chemokines, cytokines and antigen-neutralizing IgAs (49).

After evading or overwhelming this first line of defense and entering host cells, the virus activates the cellular antiviral 
defenses effectuated by hundreds of proteins (cytokines, chemokines, host restriction factors) which block different steps in the viral replication and are activated by specific cell sensors/receptors. Interferons (IFNs) via IFN-stimulated genes (ISGs) initiate innate and adaptive immune responses which alter host cell cycle, translation and apoptosis, virus entry, viral RNA availability, stability and translation, particle and budding (50).

Molecules involved in virus detection in the cytoplasm of host cells are: the retinoic acid-inducible gene-I (RIG-I), a RNA helicase with the respective cell receptors - RIG-I-like receptors (RLR); and the melanoma differentiation-associated protein 5 (MDA5), both of which have the same downstream effector: the mitochondrial antiviral signaling protein (MAVS). Besides RIG-1 and MDA5, other cellular viral RNA sensors are known: the protein kinase RNA-activated (PKR), oligoadenylate synthetase (OAS), latent endoribonuclease (RnaseL), cyclic GMP-AMP (cGAMP) synthase (cGAS) (51); PKR stops host cell translation and helps activate the NF- $\kappa \mathrm{B}$.

Early in infection the antiviral response is driven by the peroxisomal MAVS, while later the mitochondrial MAVS triggers an interferon (IFN)-dependent, sustained immune response. MAVS signaling ultimately results in $\mathrm{NF}-\kappa \mathrm{B}$ (and other pro-inflammatory pathways) activation which translocates to the nucleus and activates the transcription of genes encoding IFN- $\alpha / \beta$, cytokines, many antiviral proteins, and RIG-I/MDA5 in a positive feedback loop (52).

Following activation, IFN- $\alpha / \beta$-type I IFNs are produced in and activate most cells, while type III IFN (IFN- $\lambda$ ) mostly mucosal cells; they activate very similar IFN-stimulated genes (ISGs). IFN signaling occurs very fast since it does not require new protein synthesis; all IFNs use the Janus kinase (JAK) - signal transducer and activator of transcription (STAT) pathway. pDCs produce most of the IFN- $\alpha$ during an infection; IFN- $\gamma$ bridges the innate and adaptive immune responses, helps regulate immune function, and is mostly secreted by activated T cells and natural killer (NK) cells (51).

TLRs from endosomes recognize viruses, while TLRs from cell membrane typically recognize bacteria. MAVS and the TLR adaptor MyD88 activate cell-specific transcriptional pathways, with pro- or anti-inflammatory profiles (ex macrophages vs. fibroblasts) (53).

All nucleated cells are thought to have RLR and PKR receptors for viral nucleic acids, while toll-like receptors (TLRs) are present in myeloid dendritic cells (mDCs) - TLR3/7 and plasmacytoid dendritic cells (pDC) TLR7/8, and also in endosomes of most cells (54).

TLR4 interacts with with the adaptor protein MyD88 and activates the mitogen-activated protein kinase (MAPK) and the NF- $\mathrm{NB}$ signaling pathway. The c-Jun NH2-terminal kinases (JNK), the signal-regulated kinases (ERKs), the p38 MAPKs, are major MAPKs with important roles in innate immunity (55).

SARS blocks antiviral defenses and the IFN production in multiple ways, at multiple sites, many involving RIG-I and MAVS (50): i) after transcription the coronaviral dsRNA is protected from detection by storage in double-membrane vesicles; ii) $M$ protein of SARS virus localizes in membranes associated with the Golgi complex and binds to the host RIG-I, thus impeding activation of MAVS; iii) ORF3b and ORF6 move to the mitochondria and block the interaction between RIG-I and MAVS to block IFN induction; iv) the papain-like protease (PIPro) removes ubiquitin from RIG-I and downregulates type-I IFN response; v) cytoskeleton perturbations in mitochondria, with modification of the mitochondrial membrane potential and impairment of MAVS activity; vi) blocking IFN- $\beta$ production by de-ubiquitination (DUB) of RIG-1 and other viral sensors and effectors (56).

Microarrays helped identify the proteins through which viral particles can antagonize host immune responses: 13 proteins were inhibitors of MAVS (LGP2, A20, SMURF2, etc.) 14 for RIG-1 (USP3, ARL16 and RNF122) and 6 for MDA5 (USP3, ARL5B, TRIM59); RNF125 inhibited RIG-1, MDA5 and MAVS (57).

Proposed therapeutic interventions. The current therapeutic interventions for COVID-19 (18) are derived from SARS treatments; the first drugs shown in 2005 to be effective in vitro for SARS, both pre- and post-exposure, are chloroquine and hydroxychloroquine; since they were extensively studied and shown to exert pleiotropic antiviral actions (58). Chloroquine is a weakly basic substance and upon entering cells it is protonated and concentrated in acidic organelles: lysosomes, Golgi vesicles and endosomes; the subsequent increase in endosomal $\mathrm{pH}$ interferes with the terminal glycosilation of the ACE2 receptor. Besides inhibiting the $S$ protein-induced viral fusion (59), and the PIPro protease (60) chloroquine can benefit patients with porphirin extravasation (Fig. 2) by preventing orf1ab, orf3a, orf10 attack on hemoglobin (37) with porphirin formation.

Protease inhibitors target viral nsps needed for its replication, such as the RNA-dependent RNA polymerase (RdRp) inhibited by ribavirin (which also inhibits viral mRNA capping); the 3C-like protease (3CLpro) is inhibited by the lopinavir-ritonavir combination (48), which seems to have better results compared to ribavirin, which was associated with anemia, hypoxia and increased risk of death in SARS patients (61).

FDA-approved drugs and agents re-purposed for COVID-19, such as ribavirin, IFNs and corticosteroids, were shown, however, to be ineffective especially in severe $\mathrm{CoV}$ infections (48); recent data on SARS-CoV2 suggest that more specific and efficacious treatments can be administered to COVID-19 patients; Table II summarizes such proposed FDA-approved drugs and Fig. 3 offers a graphic presentation.

Among COVID-19 proposed drugs already approved for other pathologies, GR 127935, a known potent entry inhibitor of Ebola and Marburg viruses, binds the SARS-CoV-2 receptor ACE2 and also is a selective 5-HT1B/1D receptor antagonist, making it useful in patients with hypotension and tachyarrhythmia, when administration of vasopressors is questionable.

Agents that bind the SARS-CoV-2 spike protein and are known to reduce lung inflammation, include GSK1838705A, BMS195614, GSK1838705A, which inhibit the insulin like growth factor-1 receptor and are used in cancer.

For blocking the ACE2 receptor, three FDA-approved drugs are proposed: TNP, an inhibitor of tyrosine kinase, IP6K and Akt pathways, which can also shown to inhibit MERS infection; eptifibatide acetate, an inhibitor of platelet aggregation already tested in septic shock; and the 
A

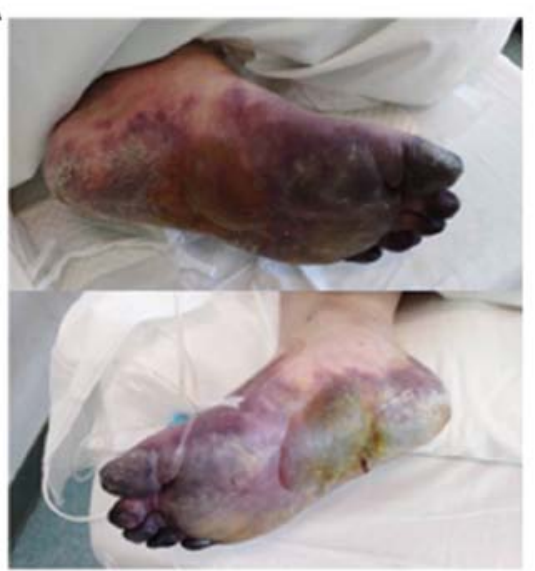

B

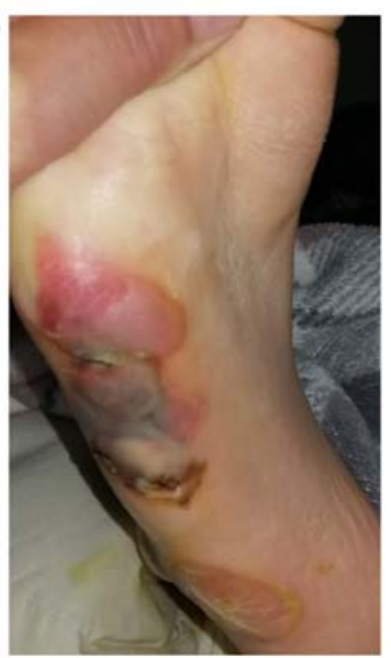

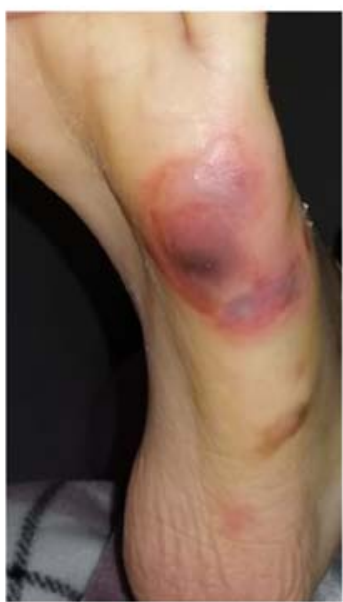

Figure 2. Severe COVID-19, interstitial hemorrhage, porphyria, necrosis. (A) Bullous porphyria and necrosis in literature (39). (B) Our own experience.

Actions of drugs and host cell defences against SARS-CoV/2

Spike S protein binding

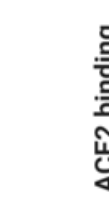

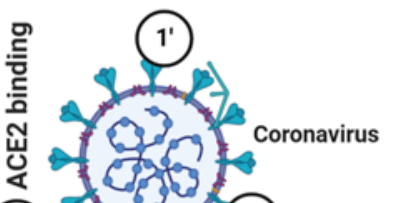

1'-hydroxychloroquine, azithromycin; KT185, KT203,

GSK1838705A, BMS195614, RS504393

2- nona-arginine, camostat mesylate
1-Eptifibatide acetate, TNP, GNF5, GR 127935, RS504393,

Syncitium

formation

GNF5/imatinib

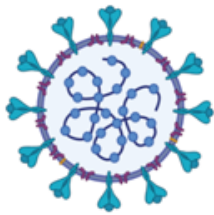

(7) betaferon, poly I:C, EK41

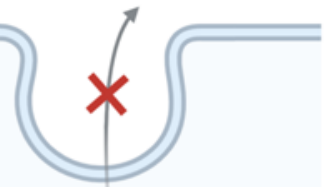

(6) assembly arbidol, tamoxifene, terconazole

\section{amiodarone} and budding.

Cytoplasm

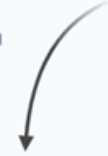

Clathrin

(n)

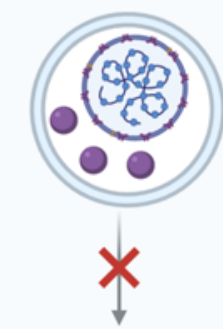

2* Endosome

acidification; viral genome release.

chloroquine, bafilomycin fexophenadine, L-arginine

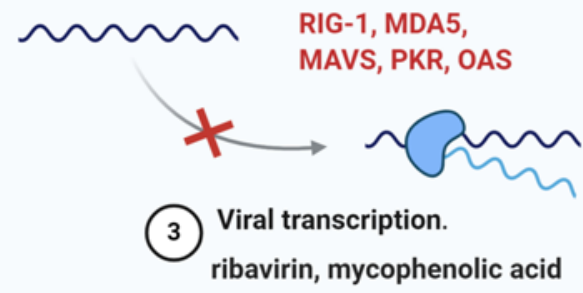

4 - darunavir, nelfinavir, saquinavir, rosuvastatin, montelukast, fexofenadine, chloroquine, formoterol, remdesivir, cloperastine vigabatrin, methotrexate, nicergoline, phenazopyridine, pemirolast lopinavir, curcumin, anisotine and vasicoline, Phycocyanobilin, Riboflavin, Cyanidin, Daidzein, Genistein, Nigellidine, $\mathrm{a}$ - Hederin

(4) Viral post-translational modification / viral proteases
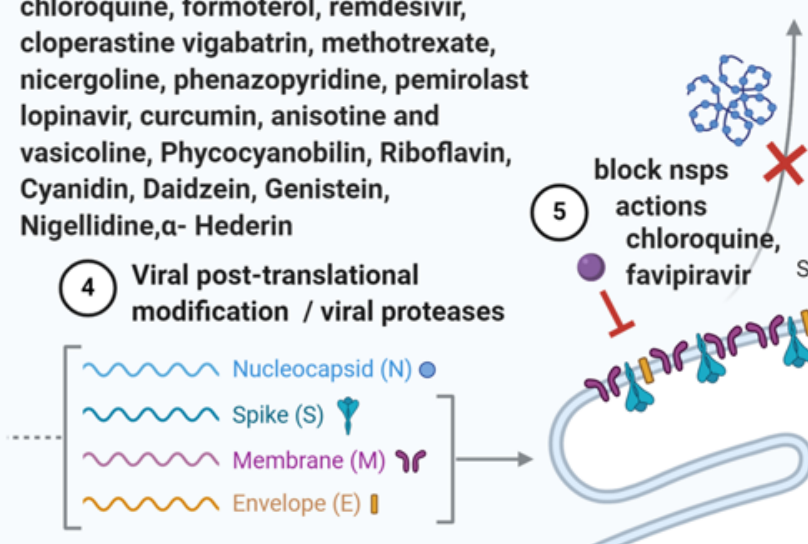

favipiravir<smiles>C1CCC1</smiles>
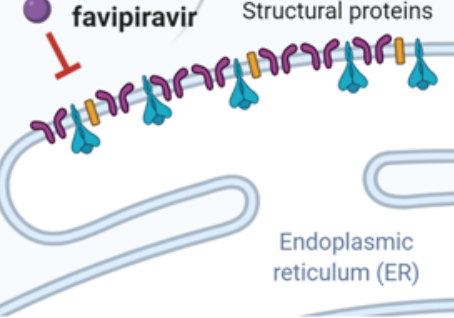

Endoplasmic reticulum (ER)

Figure 3. Antivirals and their actions.

Abelson (Abl) kinase inhibitor GNF5, known to inhibit replication of Dengue virus, which deserves further attention. It was shown that Abl2, but not Abl1 is necessary for replication of SARS/MERS CoV (66) as the virion and endosomal membranes fuse via a cathepsin L-dependent mechanism; the Abl2 kinase inhibitors GNF5/GNF2/imatinib inhibit the 
Table II. FDA-approved drugs with SARS-CoV2 antiviral actions.

\begin{tabular}{ccc}
\hline Substance analyzed (Ref.) & $\begin{array}{c}\text { Viral molecule inhibited; } \\
\text { mechanism }\end{array}$ & $\begin{array}{c}\text { Method and/or software used for testing } \\
\text { FDA approved drugs }\end{array}$
\end{tabular}

Hydroxychloroquine and azithromycin (59)

Eptifibatide acetate, TNP, GNF5, GR 127935, RS504393 (62)

KT185, KT203

GSK1838705A,

BMS195614, RS504393 (62)

Darunavir, Nelfinavir, Saquinavir, Rosuvastatin (63)

Montelukast, Fexofenadine (63)

Chloroquine,

formoterol, 16 other FDA-

approved drugs (60)

Remdesivir $(-13.1 \mathrm{KJ} / \mathrm{mol})$

cloperastine (-10.4)

vigabatrin $(-10.2)$

methotrexate (-6.9)

Remdesivir (-18.6 KJ/mol)

vigabatrin $(-12.1)$

cloperastine (-10.1) nicergoline (-9.0) phenazo-

pyridine (-8.4) (64)

Pemirolast (65)

Chloroquine (37)

Favipiravir (37)
Protease:

Spike (S) Protein - binding motifs of ACE2 receptor;

ACE2 receptor protein

of host cells

binding site

S-protein (RBD of spike protein)

binding site

anti-inflammatory

Mpro, central site

Protease:

Mpro, terminal site

Protease:

papain-like protease

(PLpro)

Protease

3CLpro (PDB ID 6LU7)

\section{Protease}

6 Y84 - main protease with

unliganded active site

Protease; RNA Replicase inhibitor

Accessory proteins prevents binding of orflab, ORF3a, ORF10 to heme,

ORF8, surface

glycoproteins to porphyrins

Accessory proteins:

inhibits binding of $\mathrm{E}$ protein,

ORF7a to porphyrin, prevent

virus entering host cells
Virtualized quantum mechanical modeling

High-throughput virtual screening used to investigate LOPAC library drugs

Software: PyRx, Open Babel, AutoDock Vina, PyMol, GROMACS; online resources SWISS MODEL, HADDOCK, RCSB PDB, NCBI, ProCheck at RCSB validation server, ProSA-web, SAVES-Verify3D server

Structure-based drug repositioning

Structure-based drug repositioning

Homology model of the protease based on SARS-coronavirus PLpro structure; drugs docked in $\mathrm{S} 3 / \mathrm{S} 4$ pockets of active site Connectivity map and the docking configurations used to simulate the docking bonding energy between antiviral and the respective protease in $\mathrm{KJ} / \mathrm{mol}$

Used PyRx for loading and visualising the SDF files for the ligands and the AutoDock Vina tool for testing the docking on two target proteins 6LU7 and 6Y84 from PDB

\section{Using COVID-19 Docking Server}

Simulated molecular docking of viral proteins with human heme or porphyrins with (LibDock tool) of Discovery-Studio 2016

Simulated molecular docking of viral proteins with human heme or porphyrins with (LibDock tool) of Discovery-Studio 2016 fusion of the viral and endosomal membrane, an early stage of viral infection. GNF5/GNF2/imatinib also inhibit the formation of cell syncitia before the hemifusion step, effectively blocking membrane fusion and viral entry (67).

Finally, 3 drugs deserve special attention for COVID-19 treatment: KT185 and KT203 which bind the S protein and are potent, selective inhibitors of $\mathrm{a} / \mathrm{b}$-hydrolase domain containing 6 (ABHD6), a transmembrane serine which hydrolases the endogenous cannabinoid 2-arachidonoylglycerol (2-AG), and more importantly decrease macrophage activation.
The third drug is probably the best viral fusion inhibitor, RS 504393, which can bind both the SARS-CoV-2 S protein and its receptor ACE2 and is used for treating lung injury and bronchial wall thickening; moreover, it is also a selective antagonist of the monocyte chemoattractant protein-1 (MCP-1) receptor CCR2, blocks the upregulation of pronociceptive, pro-inflammatory interleukins IL-1 $\beta$, IL-18, IL-6, and as such are very useful for decreasing the 'cytokine storm' and the associated neuropathic pain (patients hypersensitive to touch).

Besides FDA-approved drugs, a variety of natural compounds have been investigated for their antiviral actions 
Table III. Natural compounds with antiviral actions.

Viral molecule inhibited;

Substance analyzed (Ref.) mechanism

Method and/or software used for testing

Anisotine and vasicoline of

Justicia adhatoda (65)

Phycocyanobilin, Riboflavin, Cyanidin,

Daidzein, Genistein (69)

Curcumin (70)

For 6LU7: Nigellidine -6.29 Kcal/mol; chloroquine -6.29; OH-chloroquine -5.57; favipiravir -4.23; For 2GTB:

$\alpha$-Hederin $-6.50 \mathrm{kcal} / \mathrm{mol}$;

chloroquine -6.20; OH-chloroquine -5.51; favipiravir -4.12 (68)
Protease;

RNA Replicase

inhibitor

Protease (Mpro);

RNA Replicase

inhibitors

Protease

inhibitor

Proteases

(3CLpro and

Mpro)

6LU7 and 2GTB

inhibitors
Using COVID-19 Docking Server

COVID-19 Docking Server to

inhibit Mpro and RdRp

Structure of metabolite and COVID_19 protease

from PubChem and Protein Data Bank (PDB); molecular docking by MVD (Molegro Virtual Docker)

Docking of compounds from Nigella sativa

and drugs performed with Molecular Operating

Environment software (MOE) on SARS-CoV2, one advantage being that some plants contain more than one active ingredient (65); in the case of Nigella sativa its main active substances, nigellidine and $\alpha$-Hederin compare positively to either chloroquine or hydroxychloroquine based on their binding energy with viral proteases (68), more information is given in Table III.

Local treatment and IFNs. Based on the observation that the host IFN response is delayed in $\mathrm{CoV}$ infections, with subsequent over-activation of neutrophils in the lung and vascular leakage (54), IFN-stimulating substances administered by inhalation showed efficacy against SARS and MERS in vitro and in vivo. Inhaled substances have the advantage of lower volume of distribution (ASL has a volume of 20-30 ml) and can act early in COV infection during the viral fusion process, inhibiting the binding of its $\mathrm{S}$ protein to the host receptor (71).

One such substance is polyI:C, a TLR3 agonist shown to induce differentiation of $\mathrm{mDC}$, promote Th1 activation with IL-12 and type I IFN production, the activation of the innate immune response and reversing the PGD2 effects in the lungs (72,73). A shortcoming of the polyI:C may be its requirement for either RIG-1 or MDA5 activity, which are known to be inactivated by coronaviruses and render polyI:C ineffective post-infection, limiting it to a prevention drug (74).

A very potent inhibitor of $\mathrm{CoV}$ fusion is nona-L-arginine with high affinity for furin (effective at concentrations of $40 \mathrm{nM}$ ); hexa- and hepta-peptides of the basic aminoacids arginine and lysine also showed excellent inhibition of viral fusion (75).

Another intranasal-administered peptide, EK1, which contains the heptad-repeat HR2 from the binding motif of the $\mathrm{S}$ protein has inhibited infection by many human coronaviruses (46); its administration in mice reduced lung viral titers by 1,000-fold 2014 (76) and its lipidation, EK1C4, resulted in much greater potency, inhibiting the cell-cell fusion mediated by $\mathrm{S}$ protein with $\mathrm{IC}_{50}$ of $4.3 \mathrm{nM}$; its protective effect manifested half an hour after and 6 hours before exposure to coronavirus (46).

IFN can also be administered directly to patients via inhalations, however, affinity amino acids have showed limited benefits depending on the timing of administration and prompts further analysis of IFN actions.

Similarly to the neutrophilia and lymphopenia observed in severe COVID-19 patients, fatal SARS infection is associated with high IFN and ISGs expression and low T cell and antibody activity, while viral clearance needs increased $\mathrm{T}$ cell responses (25).

The immune response of $\mathrm{CoV}$ patients is imbalanced, with over-stimulation of the monocyte-macrophage line and decreased $T$ cell activation; while early administration of IFN-1 has protective effects, in later stages administration of IFN, with the possible exception of IFN- $\gamma$, is associated with increased neutrophil infiltration in the lungs. This is due to the selective activation of ISGs in macrophages, but not in $\mathrm{B}$ or $\mathrm{T}$ cells, since signaling in these cells requires the myeloid differentiation factor 88 (MyD88), a key molecule used in all TLR signaling pathways of adaptive immunity except for TLR3 which is present in all endosomes (77).

In animal models of lethal COV infection, the immunopathological events are mostly IFN-I-dependent and independent of viral replication; IFN- $\alpha / \beta$ receptor (IFNAR) receptor ablation or neutrophil depletion avoided lethal infection but did not affect the viral load. TNF inhibition improved lymphopenia, which is not unexpected since IFN-I sensitizes $\mathrm{T}$ cells to apoptosis.

It was shown that an important role in modulating the inflammatory response is played by two proteins containing the Toll or interleukin (IL)-1 receptor (TIR): MyD88 and the TIR domain-containing adaptor-inducing interferon (TRIF) (78). For controlling inflammation both MyD88 and TRIF proteins 
are required, since the release of the anti-inflammatory IL10, IL19, endothelial lipase, metalloproteinase inhibitor 1 (Timp1) and plasminogen activator inhibitor 1 (Serpin1) is prevented in the absence of either one, resulting in excessive pro-inflammatory modulation.

During early $\mathrm{CoV}$ replication in non-lethal models, pDCs are the major IFN-I producers, and pDCs sense coronaviral RNA via TLR7 within endosomes (54). The same author shows that the coronavirus endonuclease (EndoU) from nsp 15 has a key role in preventing early induction of innate responses, by removing the viral dsRNA that would otherwise trigger host cell dsRNA responses, including IFN, PKR and OAS/RNase L, and delaying the viral RNA cytoplasmic sensing mediated by MDA5.

During early stages of SARS infection, IFN- $\gamma$ presence is associated with viral clearance and infection resolution; IFN- $\gamma$ is synthesized mainly by activated $\mathrm{T}$ cells and natural killer (NK) cells (79). IFN- $\gamma$ (type II) and IFN- $\alpha / \beta$ (type I) have synergistic actions; given alone neither inhibits viral replication, but administration of both inhibited viral replication by 3000 -fold at $24 \mathrm{~h}$, with stronger inhibition at 48 and $72 \mathrm{~h}$.

Oligonucleotide arrays were used to study the ISGs regulated by IFNs; all IFNs induced complement component C1r, IFN-induced nuclear phosphoprotein, vascular endothelial growth factor (VEGF)-related protein (VRP or VEGF-C), and phospholipid scramblase, an apoptosis promoter; its levels increased 8 -fold by IFN- $\alpha, 10$-fold by IFN- $\beta$, and 3 -fold by IFN- $\gamma$ (80). Additionally each IFN preferentially induced specific molecules: IFN- $\alpha$, somatic cytochrome $c$; hepatitis C-associated p44; pyridoxal kinase; and lysosomal acid lipase (LIPA); IFN- $\beta$, clathrin-like protein, PKR, hypoxia-inducible factor-1 (HIF-1 $\alpha$ ) which regulates apoptosis and cell response to hypoxia via expression of VEGF, p53, p21; IFN- $\gamma$, mitochondrial 3-ketoacyl-CoA thiolase; poly (ADP-ribose) polymerase; proton-ATPase-like protein.

Both type I and type II IFNs increase expression of the $\mathrm{CH} 25 \mathrm{H}$ gene which codes for the enzyme Cholesterol-25-hydroxylase, which converts cholesterol into 25-hydroxycholesterol (25HC) (50), an oxysterol with antiviral effects via alteration of membrane properties, inhibition of sterol biosynthesis and prenylation (priming) of virus and host proteins. However, 25HC production by macrophages also has a central role in regulating the immune system, and at $\mathrm{nM}$ concentrations it suppresses the IL-2 mediated proliferation of B cells and inhibits IgA production (81).

Another possible pathological modification induced by the $\mathrm{CoV}$ in susceptible patients is the activation of alternatively activated macrophages, M2, which normally have anti-inflammatory actions and are involved in the wound-healing processes (82), but were also found in the lungs of mice lacking STAT1 signaling pathway (STAT1 knockouts), which after the SARS-CoV infection, had an increased number of M2 macrophages in their lungs, activated via the STAT6 pathway, and developed pulmonary fibrosis (83).

The modifications induced by the SARS-Cov infection in host cells were also investigated via a library screen of small interfering RNA (siRNA) targeting the human kinome (84). Besides the expected activation of pro-inflammatory pathways (production of NO and ROS in macrophages, IL-2, IL-6,
IL-8 and IL-17) there was also an increase in the metabolic pathways of complex lipids (inositol phosphate, nicotinate, nicotinamide), intermediates needed in SARS-CoV infection and probably linked to prenylation. The strongest proviral activation was seen in the $\beta 2$ subunit of the coatomer protein complex (COPB2) followed by inositol hexaphosphate kinase 1 (IHPK1); abelson kinase 1 (ABI1); diacylglycerol kinase epsilon (DGKE); cyclin-dependent kinase 5 regulator (CDK5R2); protein kinase $\mathrm{C} \iota$ (PRKCi). Among antiviral molecules were found the diacylglycerol kinase $\delta$ (DGKD), the double-stranded RNA-activated protein kinase (PKR); cyclin-dependent kinase 6 (CDK6) and most MAPKs with the exception of MAP3K11, which is weakly proviral; ABl1 inhibitors and molecules acting on lipidic and glucidic metabolism are thus important.

Another factor influencing IFN actions is the hemoglobin $\beta$-chain which was shown to stimulate IFN- $\beta$ production via RIG-1, including potentiating of RIG-I ubiquitination; hemoglobin is present in lung, kidney, peripheral blood mononuclear and other cell lines $(38,85)$, and SARS-CoV2 nsps can bind to and degrade hemoglobin (37).

Indoleamine 2,3-dioxygenase (IDO), stimulated by IFN $-\gamma$ and inhibited by TLR activation and allergens plays an important role in immune suppression (normally prevents hyper-inflammation and autoimmunity) by inhibiting $\mathrm{T}$ cell activation and polyclonal proliferation of $\mathrm{T}$ cells, mostly through degradation of tryptophan and kynurenines; its role in SARS-CoV2 infection was not explored but likely is important (86). Activation of IDO is strictly dependent on prior expression of Arginase 1 and the resulting polyamines, with immunosuppressive actions (87); while NO is an IDO inhibitor; the role of IDO in the SARS-CoV2 infection and its immune evasion has not yet been explored.

The data above confirm that in severe $\mathrm{CoV}$ infection the host immune system is mounting an imbalanced response to infection which powerfully favors neutrophils/macrophages and inhibits the adaptive cellular response; early events include hindered pDCs activities and over-activation of macrophages with induction of IFN-I expression and autocrine over-stimulation; this may be due to 25-hydroxycholesterol or IDO overactivation, Myd88 inactivation by the virus, hemoglobin degradation and/or simultaneous actions of other viral molecules (EndoU).

However, it is possible that the delayed IFN response followed by neutrophil over-activation is simply due to the lack of activation in the early stage of infection of the peroxisomal MAVS necessary for early IFN production (52), and this observation gains more weight as peroxisome function declines significantly in tandem with cellular senescence, advancing age, and age-related co-morbidities (88). Peroxisome senescence is associated with dramatic changes in their protein import capabilities, functional integrity, ability to process ROS, regulation of growth and division of other organelles, decreased ability to oxidize fatty acids, accumulation of free fatty acids and diacylglycerol, followed by reorganization of protein kinase $\mathrm{C}$ (PKC) signalling (89).

This fact is related to the important metabolic functions of peroxisomes, which have $>50$ enzymes in their matrix performing critical metabolic functions besides production and degradation of $\mathrm{H}_{2} \mathrm{O}_{2}$ including fatty acid oxidation, 
synthesis of specialized lipids, including anti-inflammatory docohexaenoic acid and degradation of pro-inflammatory leukotrienes and recently it was shown that multiple viruses interfere with antiviral signaling dependent on peroxisomes, examples being the accessory protein Vpu of HIV-1 which annihilates peroxisomes (90), the VP16 protein of HSV-1 which blocks the peroxisomal MAVS (91), also the hepatitis C virus protein NS3-4A, the capsid of the Dengue and West Nile virus, and the vMIA protein of cytomegalovirus (92).

Peroxisomal MAVS stimulates ISGs via IRF1 and IRF3 in an IFN-independent manner and does not induce IFN production in macrophages, which is dependent on mitochondrial MAVS. Interestingly, cells lacking either peroxisomal or mitochondrial MAVS had an unusual biphasic behavior, restricting viral replication in the first $24 \mathrm{~h}$, but not at $72 \mathrm{~h}$, and showing that both organelles are necessary for viral clearance (53). The functional status of peroxisomes can be correlated both with age and the severity of SARS-Cov2 infection, and is impaired by poor oxidative status, low cellular $\mathrm{pH}$ (acidosis) and/or hypoxia which is also seen in patients with chronic pathologies or genetic deficiencies.

$p H$-dependent viral actions. At the surface of the respiratory epithelium low $\mathrm{pH}$ favors viral entry and replication by impairing the actions of the AMPs from the airway surface liquid (ASL), which have $\mathrm{pH}$-sensitive antimicrobial functions, with the $\mathrm{pH}$ of ASL being actively regulated by bicarbonate transport (49); another pH-lowering viral activity is the formation of cell syncytiums. Lower intracellular $\mathrm{pH}$ favors the activity of the proteases needed for viral replication, decreases the mitochondrial membrane potential and inactivates MAVS, which is essential for IFN and $\mathrm{NF \kappa B}$ activation and production of antiviral protein switches. In addition, low $\mathrm{pH}$ promotes oxidative phosphorylation to anaerobic glycolysis with increased mitochondrial ROS production via related cellular pathways (93).

The modifications in the cellular redox state, ionic balance and $\mathrm{pH}$ which are simultaneous with the actions of specific molecules in a pathway are not often measured or considered during lab experiments, but in the context of dual or multiple regulators they may have important consequences, one such example being the effect of hemoglobin ( $\mathrm{Hb})$ on IFN production (85). While exerting a direct inhibitory effect on MDA5 which inhibits IFN production, $\mathrm{Hb}$ also modifies a cell redox state, promotes the RIG-I pathway and stimulates IFN production; the increase in ROS by $\mathrm{Hb}$ is stimulated only by the microbial and not by the host protease.

Additionally, the infectivity of $\mathrm{CoV}$ and other enveloped viruses is known to be impaired by an increase in endosomal $\mathrm{pH}$ in a dose-dependent manner; mild bases such as lipophilic amines or amphiphilic drugs with a tertiary amino group can accumulate in acidic organelles via protonation, where they neutralize internal $\mathrm{pH}$, alter the properties of the adjacent membranes and inhibit multiple processes occurring in the respective compartment (94); this was also observed with administration of bafilomycin or ammonium chloride ( $\mathrm{NH} 4 \mathrm{Cl})$ in cell cultures at $5 \mathrm{mM}$ concentrations $(58,72,95)$. In case of $\mathrm{CoV}$ the elevated endosomal $\mathrm{pH}$ blocks the cysteine proteases cathepsin B and $\mathrm{L}(\mathrm{CatB} / \mathrm{L})(45)$ and inhibits the $\mathrm{S}$ protein entry into host cells. Furthermore, $\mathrm{NH} 4 \mathrm{Cl}$ and chloroquine (also a weak base) impair the glycosylation of ACE2, an additional mechanism for blocking viral fusion.

The $\mathrm{pH}$-dependent fusion of various viruses endocytosed into host cells by non-coated vesicles (caveolas) or in association with clathrin is well-documented (96); additionally $\mathrm{CoV}$ and influenza viruses can fuse with host cell membranes via anchoring cell receptors and internalization in the lipid bi-layer, a process blocked by constituent hydrolaze $\mathrm{CH} 25 \mathrm{H}$, methyl- $\beta$-cyclodextrin, a cholesterol-sequestering drug, simvastatin and possibly other lipophilic statins.

Low $\mathrm{pH}$ is affecting essential aspects of the native immune response - neutrophil activation, chemotaxis, production of ROS, NO and phagocytosis, apoptosis, cytokine production, activation of transcription factors by binding to DNA, and also decrease of lymphocyte function, lymphokine secretion and activation, while hypoxia is potentiating these actions (97-101); acidosis is associated with increased need for intensive care and hospitalization (102). In addition, a low extra- and intra-cellular $\mathrm{pH}$ not only favors viral infection, but also impedes the antiviral action of known medication.

$p H$ modifies the activity of antiviral medications. Many proteins undergo conformational changes of their tertiary and quaternary structure induced by ionic changes $\left(\mathrm{Ca}^{2+}, \mathrm{H}^{+}, \mathrm{Fe}^{2+}\right.$ and $\left.\mathrm{Mn}^{+}\right)$and $\mathrm{pH}$ modifications. Such modifications are documented for the main protease (Mpro) of SARS-CoV2 during its binding to protease inhibitors at $\mathrm{pH} 4.0-8.0$, and it was shown that they were $\mathrm{pH}$-dependent, with different binding energy (stability of protein complex) and specific bonding type/atom interaction (103).

Small modifications in $\mathrm{pH}$ can have critical consequences as was shown with arbidol, a broad-spectrum antiviral which binds to the influenza virus haemagglutinin (HA), induce a 0.2 unit $\mathrm{pH}$ modification and blocks viral fusion; consequently some influenza strains developed a HA which disrupted the drug-HA bond with loss of medication effectiveness (104).

More aspects of $\mathrm{pH}$ modifications in viral infections are discussed below; re-establishing physiological $\mathrm{pH}$ levels (7.35-7.45) is an important therapeutic consideration in ALI/ARDS.

Genetic and translational factors involved in severe COVID-19. An important question is whether the host genetic factors significantly impact the immune functions and the host answer to viral infection, as it was found that individual variations exist in expression of RIG-1 and other antiviral molecules (57).

Studying the bronchoalveolar lavage fluids from ARDS patients by proteomic analysis during the initial 4 days of care, survivors and non-survivors showed differences: non-survivors had decreased expression of proteins involved in immune activation, coagulation, iron metabolism, and increased protein expression of glycolysis and collagen pathways (105).

Also, an association was found between four SNPs and ARDS patients: rs78142040 of ARSD - an arylsulfatase gene involved in sphingolipid metabolism and associated with 60-day mortality; rs9605146 in XKR3 gene affecting membrane transport and red cells, neuromuscular and central nervous systems, was associated with susceptibility to ARDS; rs3848719 of ZNF335, zinc finger protein regulating 
lymphoblast proliferation, was associated with increased ARDS severity (APACHE II score); nicotinamide phosphoribosyltransferase (NAMPT) with the $-1535 \mathrm{~T}$ allele associated with decreased susceptibility to ARDS, and the $-1001 \mathrm{G}$ variant with higher susceptibility to ARDS and mortality in a Caucasian population; other pathways showing differential activation in ARDS patients were T lymphocyte signalling, calcium-induced apoptosis of T lymphocytes, B-cell development, and autoimmune thyroid disease (106).

Other genes associated with the pulmonary injury type of ARDS are POPDC3 (expressed in cardiac and skeletal muscle, role in glioma and muscular dystrophy), PDE4B (phosphodiesterase), ABCC1 (organic anion transporter of oxidized glutatione, cysteinyl leukotrienes and antiviral drugs), and TNFRS11 (TNF receptor superfamily member 11) the rs1190286 allele of POPDC3 is associated with decreased ARDS risk (107).

Using bioinformatic analysis for genetic associations with ARDS, a total of 201 genes were found predominantly involved in pathways modulating inflammation, especially linked to innate immunity, reactive oxygen species, and endothelial vascular signaling (108); it is worth noting that all these pathways are modulated by NOS.

ACE2, RAS and ACE inhibitors. First genetic markers analyzed as risk factors for ARDS pathogenesis were found in 2002 to be correlated with ACE polymorphism, with the $\mathrm{D}$ allele increasing its actions (109). The frequency of the DD genotype was significantly increased in the ARDS group, suggesting a role for the renin-angiotensin system in ARDS development. A 2004 study in a small Vietnamese population with SARS found an increase frequency of $\mathrm{D}$ allele in patients with hypoxia $(n=22)$ versus no hypoxia $(n=22)(110)$. However, a larger study $(n=168)$ evaluated the influence of ACE I/D polymorphism on SARS-CoV infection susceptibility and development of ARDS in a Chinese population and found no association between the frequency of the $\mathrm{D}$ allele and presence of infection or severe disease; the only factors associated with requirement of intensive care was age and male sex (111).

Measuring serial ACE levels in a small number of ARDS patients $(n=36)$ revealed that during the first $24 \mathrm{~h}$ the ACE levels were normal or decreased, with no difference between septic and aseptic ARDS, and after an initial decrease during the first $96 \mathrm{~h}$ ACE levels normalized by day 7; persisting low ACE levels tended to be associated with ARDS aggravation and fibrosis (112).

ACE2 is the main host receptor used by SARS-CoV2, and together with its homologue ACE, also a non-specific protease, modulate the activity of RAS, with ACE2 inactivating angiotensin II (AngII). In animal models, administration of recombinant ACE2 protects mice from lung injury and ACE-deficient mice had much better outcome in acute lung injury (113). Also in animal models with acute inflammation it was shown that the renin angiotensin system (RAS) regulates neutrophil influx and pre-treatment of mice with the RAS inhibitor enalapril and losartan decreased lung neutrophil infiltration, concomitant with bradykinin increase and angiotensin II decrease; agonists of bradykinin receptor also inhibited neutrophil chemotaxis induced by IL- 8 and pulmonary recruitment of neutrophils (114).
Angiotensin II activates NF- $\kappa \mathrm{B}$ in monocytes with proinflammatory effects, and RAS inhibitors also decrease NF- $\kappa \mathrm{B}$ activation and neutrophil chemotaxis (115). Moreover, angiotensin converting enzyme (ACE) affects pulmonary vascular tone and permeability, epithelial cell apoptosis, and lung fibrosis via fibroblast activation so that RAS inhibitors may be beneficial in ARDS.

ACE2 inactivates AngII and was shown to protect mice from sepsis-induced ALI, by downregulating RAS which is involved in pulmonary hypertension and pulmonary fibrosis; ACE2 expression increases after IFN-I administration. SARS-CoV infection produces a rapid downregulation of ACE2 expression at cell surface, ACE2 protein levels and RNA expression $(83,116)$.

Another observation is that ACE inhibitors increase levels of the peptide Ang-(1-7), which inhibits allergic inflammation by suppressing ERK- and NF- $\mathrm{B}$-dependent pathways $(117,118)$.

Translating data from animal models to clinical practice shows sometimes important differences, and we have contradicting results in clinical trials involving RAS and ARDS. A South Korean study with 182 patients (115) showed that mechanically ventilated patients on RAS inhibitors had better survival rates at 30 days than patients not receiving them; however at 90 days there was no significant difference in mortality between the 2 groups, and patients on RAS inhibitor required longer ICU stay and mechanical ventilation.

More studies are needed to inform decisions on the use of RAS inhibitors in CoV infected patients; we should note that ACE inhibitors increase bradykinin levels, responsible for the associated cough and angio-edema and also a potent vasodepressor (119), restricting their use in patients with COVID-19 ARDS and hypotension. The risk for bradykinin-mediated adverse reactions was found to be linked to the levels of aminopeptidase $\mathrm{P}$, which catabolizes bradykinin and was significantly lower in hypertensive patients with a history of angio-oedema during ACE inhibitor treatment (120); the aminopeptidase $\mathrm{N}$ is also a receptor for some strains of coronaviruses (121).

\section{The combination of arginine-ascorbate}

There is ample data suggesting that the severity of the COVID-19 is less related to the viral replication itself than to the host responses to the infection: delayed IFN production, increased neutrophils and cytokines in the lung creating a pro-inflammatory, pro-apoptotic milieu, combined with lymphopenia, acidosis, coagulation and vascular endothelium modifications and defective tissue repair with fibrosis in the lungs. Most treatments are focused on blocking viral replication, however, in fatal cases irreversible changes and deterioration occur even though viral replication is essentially blocked. Therapeutic interventions which combine agents for pleiotropic actions rather than single agents acting on well-defined pathways are more likely to improve patient outcomes.

Analyzing genes with modified expression in ARDS evidenced 201 genes, predominantly from pathways modulating inflammation, innate immunity, reactive oxygen species, and endothelial vascular signaling (108); all these pathways 
are modulated by NO generated from arginine, the only physiological substrate for NO (122).

Arginine-ascorbate has several important benefits in $\mathrm{CoV}$ infection: firstly, direct antiviral actions, secondly, improvement of leukocyte function and number, especially important in patients with neutrophilia and lymphopenia and finally it provides essential components and stimulates the mechanisms of tissue repair.

a) Antiviral actions. During the 2003 SARS epidemic medicinal NO gas, a mixture of $0.8 \% \mathrm{NO}$ and $99.2 \% \mathrm{~N}_{2}$ was administered by Keyaerts et al (123) and followed by prompt improvement in oxygenation and sustained patient benefit; following-up on this observation it was shown that NO donor compounds inhibited SARS-CoV replication in vitro, a finding replicated by another team who also observed that besides S-nitroso-N-acetylpenicillamine (SNAP), IFN also inhibited SARS-CoV replication in vitro (124), confirming results obtained by another team who showed that IFN stimulates iNOS and NO production for prompt antiviral action (125).

Interestingly, IFN- $\gamma$ stimulates NO production, and inhibition of NOS in mice resulted in conversion of a resolving infection by the ectromelia virus into fulminant mousepox (126).

NO production from arginine by the inducible NO synthase (iNOS) was shown to be essential for native immune responses in many infections and arginine availability is a critical factor for host resistance to infection (122). NO can pass through membranes, unlike complement and antibody, and is especially useful in syncytia, it can act on multiple targets increasing efficacy and preventing developing of resistance, and do not require recognition of infected cell by the immune system, which can be limited by pathogens or tissue-specific differences (127).

Reducing arginine availability either by nutrient deprivation or by specific pathogens significantly blunts the immune response, the former via impaired TLR4/MAPK pathway signalling, the latter by inducing arginase 1 via other TLRs in macrophages in an autocrine-paracrine manner involving cytokines, an immune evasion mechanism shown with mycobacteria (122) and probably also in SARS-CoV2 infection.

Arginine also directly stimulates transcription/translation of the iNOS gene leading to de novo NOS protein synthesis, and this sheds light on the 'arginine paradox' where intracellular NO production is directly related to the extracellular arginine concentration even though endogenous synthesis of arginine provides approximately half of the arginine needed by cells (128). To ensure the increased need for intracellular arginine, the cationic amino acid transporter CAT2B is induced by IFN- $\gamma$, which is stimulated by ascorbate (129). Reciprocally, the $\mathrm{pH}$ buffering action of arginine is increasing the cellular uptake of ascorbate by improving the activity of the cellular transporter of ascorbate, SVCT2, which has a pH optimum of 7.5 and is reduced to $\sim 50 \%$ when $\mathrm{pH}$ is 5.5 (130).

Ascorbate is actively accumulated in phagocytic cells where its concentration is 70-100 times higher than in plasma; it enhances chemotaxis, ROS generation, phagocytosis and viral clearance, important for minimising necrosis and tissue damage (131)
Ascorbate stimulates the synthesis and actions of antiviral NO indirectly in multiple ways, one via IFN- $\gamma$ stimulation (132), another via inhibition of HIF-1 $\alpha$ and correction of hypoxia, which significantly inhibits the availability of intracellular arginine and NO production (133); and also by synergizing with the apoptotic effects of NO (134) in virus-infected cells, and thus inhibiting viral replication. It is also important to note that all three of NOS as well as IDO (135) are heme-containing proteins which require ascorbate or another intracellular reducing agent for their activation. In this context, the observation that three accessory proteins of SARS-CoV2 - orf1ab, ORF3a, ORF10 - bind to heme followed by $\mathrm{Fe}$ inactivation and sequestration (37) deserve to be further investigated for specific anti-NOS and other IDO activities.

In the case of SARS-CoV2 infection which directly antagonizes NO production, arginine provides both the substrate for iNOS and activates its synthesis; together with ascorbate, which is necessary for iNOS activation, it prepares a new functional enzyme necessary for NO production.

b) Improving lymphocyte function and number. Lymphopenia is present in a significant number of severe COVID-19 patients (9) and its causes are strongly linked to arginine and ascorbate deficiencies.

Arginine is known to improve lymphocyte-based immunity (136). Arginine depletion due to upregulation of Arg1 in myeloid-derived suppressor cells induces T-cell anergy, decreased proliferation of T cells, low expression of CD3 $\zeta$-chain $\mathrm{T}$-cell receptor, and impairments of production of $\mathrm{T}$ cell cytokines and of upregulation of cyclin D3 and cyclin-dependent kinase $4(\mathrm{cdk} 4)$ (137). L-arginine is essential for maturation of $\mathrm{CD}^{+}$and the proliferation of $\mathrm{CD}^{+} \mathrm{T}$ lymphocytes (138). Arginine is also critical for B-lymphocyte differentiation; in transgenic mice over-expressing arginase in intestinal cells there was an impaired transition of pro- to pre-B cells in the bone marrow with marked decrease in B cell cellularity, serum IgM levels and number and size of Peyer's patches; this was reversed by arginine supplementation (139).

Noting the essential role of arginine for immunity, an arginine deficiency syndrome (ADS) was proposed, defined by pathological increase in arginase, decreased NO production, decreased arginine availability, abnormal $\mathrm{T}$ cell function including loss of $\zeta$-chain, and presence of one or more of: trauma, cancer, chronic infection, liver necrosis, pulmonary hypertension; treatment for ADS include L-arginine and the arginase inhibitors N-hydroxy-arginine (NOHA) and COX-2 inhibitors.

Ascorbate is also important for adaptive immune responses, starting with the observations that reducing environments make immune responses more efficient (140); it increases the levels of IFN produced by activated fibroblasts (141); improves neutrophil function by preserving/restoring function of their myeloperoxidase; is essential for lymphocyte development, stimulating the proliferation of NK cells (142); and has ample epigenetic effects through dioxygenases TET (ten-eleven translocases) and Jumonji C (JmjC)-domain-containing histone demethylases (131).

A comprehensive review of the actions of ascorbate including those on the immune system (131) concludes that enhancement of B- and T-cell differentiation and proliferation 


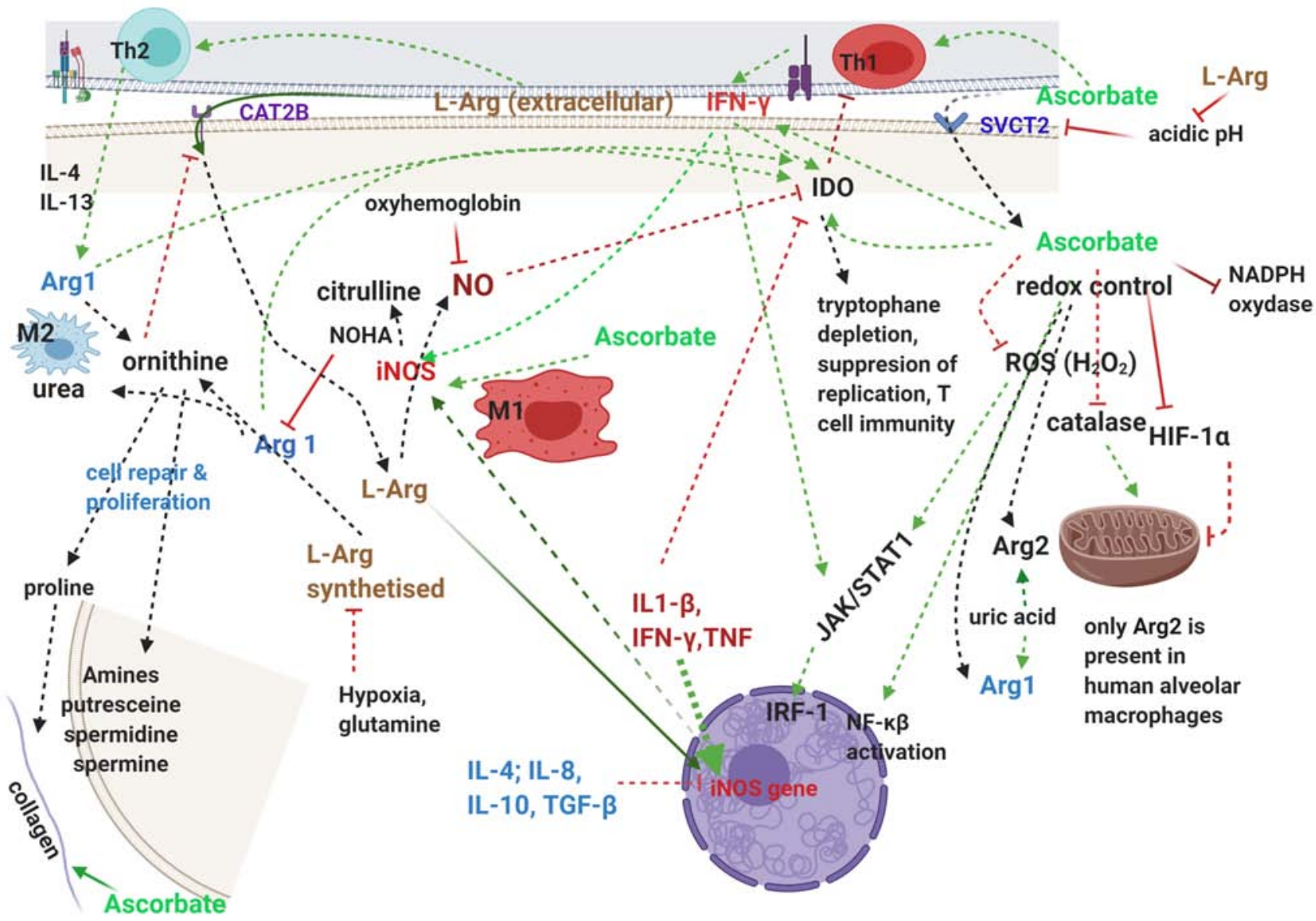

Figure 4. Antiviral actions of arginine and ascorbate.

is likely due to its effects on gene regulation; an epigenetic effect (DNA demethylation) of ascorbate on the CD8 receptor gene was also inferred in a series of lab experiments which concluded that ascorbate is necessary and sufficient for the CD8a gene transcriptional activation (140). A graphic representation of these actions are given in Fig. 4.

Multiple authors noted that administration of ascorbate in chronic granulomatous disease led to consistent improvements $(143,144)$; more recent research showed that in human granulomas depletion of arginine by arginases from macrophages was associated with T-cell suppression without affecting their viability, via downregulation of T-cells receptors (128).

Both arginine and ascorbate stimulate production of NO, which inhibits IDO (135), and its suppressive effects on lymphocyte proliferation; the simultaneous action of arginine (NO donor) and ascorbate (catalase inhibitor) is synergical for leukocytes function and especially apoptosis (134), yet another example of the arginine-ascorbate antimicrobial synergy.

Synergistic action of arginine-ascorbate for inhibiting viral replication and achieving viral clearance is shown by the combined effect of IFN- $\alpha$ (induced by NO) and IFN- $\gamma$ (induced by ascorbate) in inducing the antiviral response via ISGs, which is much enhanced when compared to either one alone $(79,145)$. This was also seen with IFN- $\beta 1$ and IFN- $\gamma(146)$ in improved apoptosis, RNA degradation and inflammatory response; and also with TNF- $\alpha$ and IFN- $\beta$ which together induced a novel synergistic antiviral state, highly distinct from that induced by either cytokine alone and involved $>850$ novel host cell genes (147); this was necessary and sufficient to completely block the replication and spread of myxoma virus in human fibroblasts and to block the spread of vaccinia virus and tanapox virus to neighboring cells.

Nitric oxide from arginine directly enhances the stimulation of ascorbic acid on $\mathrm{T}$ cell proliferation, and this interaction is especially important in $\mathrm{T}$ cell recovery after stem cell transplantation (147), where generation and proliferation of $\mathrm{T}$ cells is greatly improved by ascorbate and blocking of NOS diminished this effect (142).

To simplify the arginine-ascorbate actions in the immune response by the way of dichotomy, arginine is an essential factor for the native immune response via NO production and activation of IFN- $\alpha / \beta$ (type I) while ascorbate is critical for the efficacy of the adaptive immunity via $\mathrm{T}$ cell proliferation and function via IFN- $\gamma$ (type II); their synergy ensures both decreased viral replication and clearance.

c) Stimulation of tissue repair. It is known for decades that L-arginine supplementation (3-10 g/day) speeds wound healing and recovery after surgery (136); we also know that ascorbate is an essential cofactor for collagen synthesis, meaning that both arginine-ascorbate are required for tissue repair; additional molecules and pathways are involved in the immune response in viral infection and individual variability can also have an important role. 
In a first step for tissue repair arginine is metabolized to ornithine by arginases (Arg1/2), resulting in both proline (collagen synthesis) and biologically active amines (putresceine, spermidine, spermine) essential for cell repair and proliferation; the balance iNOS/Arg1 determines the pro- or anti-inflammatory environment and intra-cellular use of arginine. Depending on this, macrophages are polarised in M1 (proinflamamtory, cytotoxic, NO) and M2 (anti-inflammatory, proliferative, Arg1), and excessive activity of either can create pathologies; surprisingly the suppression of M2 activity in mice resulted in reduced lung fibrotic lesions in SARS-CoV infection, suggesting the virus produces a shift to M2 activities, despite the high levels of inflammatory cytokines $(82,127,148)$.

Arginine corrects the $\mathrm{pH}$ and its increased extracellular concentration helps cause a shift towards M2, and is the substrate for arginase, which is stimulated by uric acid. Arginases are activated by $\mathrm{Mn}^{2+}$ in a $\mathrm{pH}$-dependent fashion, Arg1/2 have an alkaline optimum activity of 9.0-9.5. NOHA, the arginase inhibitor, can also be oxidized to NO by many heme proteins, including hemoglobin, peroxidase, cytochromes P-450, and catalase, which is inhibited by ascorbate, which is another mechanism by which ascorbate modulates redox and metabolic reactions and NO production (133).

While NO donors (SNAP, molsidomine) or iNOS gene transfer enhance wound collagen synthesis in a dose-dependent manner, high levels of NO strongly impair collagen synthesis probably due to inhibition of arginase.

Ascorbate helps reduce inflammation by limiting expression of pro-inflammatory cytokines, reducing CRP in individuals with CRP $>1.0 \mathrm{mg} / 1$ (149); it scavenges ROS and reduces the oxidative stress on mitochondria (150), improves intracellular $\mathrm{pH}$ via decreasing lactate (151), decreases cell apoptosis and tissue necrosis also by inhibiting HIF-1 $\alpha$ (152), which is stimulated by IFN-I (80); hypoxia by inhibiting arginine intracellular synthesis is a deleterious factor for tissue regeneration.

To get a good perspective on the dose needed of arginine-ascorbate, we note that the daily plasma flux of arginine is about 22-25 $\mathrm{g}$ with 5-6 $\mathrm{g}$ from diet (153), the majority of arginine is synthesized in the liver and kidney (15-20 g daily) from citrulline in the urea cycle, $\sim 10 \%$ is used for creatine synthesis and $1 \%$ for NO generation (133). Pharmacological doses of up to $30 \mathrm{~g} / \mathrm{day}$ for 2 weeks administered either intravenously or enteral in multiple clinical studies appear to be well tolerated by healthy individuals and cancer patients without major side effects; significant elevation in IGF1 was the only modified biomarker (153).

Ascorbate is sufficient in normal situations in doses of $50-250 \mathrm{mg}$ daily for maintaining plasma levels $>30 \mu \mathrm{g} / \mathrm{ml}$, however, during stress and infections the need for ascorbate intake exceeds $1,000 \mathrm{mg} / \mathrm{day}$ and its intestinal absorbtion is optimal when administration is fractionated at 250-350 mg per dose or in extended release forms (calcium ascorbate and slow-release micronised preparations) (154).

In our experience (155) an effective antiviral regimen is the combination arginine+extended release vitamin $\mathrm{C}$, in doses of 1,000 mg L-arginine and 250-500 mg calcium/sodium ascorbate (Ester-C) or Cetebe (GSK) or other modified release vitamin $C$, at least 3 times a day each.
We have found this treatment effective in many types of viral infections, including common cold and flu (many of which are caused by coronaviruses), herpes labialis, zona zoster, and hepatitis $\mathrm{C}$, including a chronic hepatitis $\mathrm{C}$ patient who had significant viral loads after 2 treatments with ribavirin+interferon, and undetectable at 5 years after intravenous arginine-ascorbate.

Arginine-ascorbate in severely ill patients. Metabolic acidosis is associated with hyper-inflammation in ARDS patients, and administration of sodium bicarbonate for balancing $\mathrm{pH}$ can be limited by electrolyte imbalance and/or cardiovascular pathology. Arginine administration can improve $\mathrm{pH}$ via the buffering action of $\mathrm{NH}^{+}$groups and additionally can provide an immunity boost to septic patients, however, the formation of NO (nitric oxide), which may induce relaxation of the vascular smooth muscle has raised concerns $(156,157)$.

A very thorough review of arginine use in critical care has analyzed both the mechanistic concern of possible NO-induced vasodilatation, alongside other actions that arginine has in the critically ill patient. This study has importantly discussed the multiple clinical trials and reports of arginine use in septic patients (158). During critical illness there is a severe arginine deficit following a $2 / 3$ reduction in arginine synthesis and increased degradation due to a 4 -fold increase of arginase activity, so that arginine becomes an essential need for supplementation (158). Decreased arginine is especially deleterious for the immune system, which produce excessive myeloid suppressor cells which induce a pro-inflammatory state and suppress $\mathrm{T}$ lymphocytes, with reduced number of $\mathrm{CD} 4^{+}$cells which are also functionally deficient, as they lack the $\zeta$-chain of its receptor.

Clinical trials found that arginine shortened hospitalizations and decreased infections, and in severe sepsis (159) improved outcomes and decreased mortality; it also reversed septic shock without hemodynamic instability (160).

A better assessment of septic shock patients can be done by using the ratio of arginine and its metabolite asymmetric dimethyl arginine (ADMA), which can block NO production and act as vasoconstrictor; a declining arginine/ADMA ratio was associated with increased mortality (161); while an increasing arginine/ADMA ratio in septic patients improved mortality $(162,163)$. Also important is a report showing that intravenous administration in critically ill patients of supra-physiologic doses of arginine did not produce hemodynamic instability (164); this may be due to a preferential uptake in septic patients of arginine by leukocytes compared to endothelial cells.

The review concludes that arginine is safe to administer and beneficial in critically ill patients, contributing to resolution of infection and improving morbidity and mortality (158).

Adding ascorbate makes administration of arginine even safer; in septic mice ascorbate administration prevented the impaired vasoconstriction and angiotensin actions and excessive vasodilation as much as the iNOS gene knockout, and greatly increased survival (165), seemingly by inhibiting excessive NO production.

An important fact is that ascorbate, which is known to be decreased in septic patients, is a cofactor required for adrenal synthesis of hormones and neurotransmitters including 
cathecholamines (norepinephrine) and vasopressin (131), physiological vasopressors which otherwise need to be administered.

In septic patients ascorbate was shown to decrease mortality especially in the hyperinflammatory subphenotype characterized by high leukocyte count $(>15,000 / \mathrm{ml})$ and fever $\left(>37.5^{\circ} \mathrm{C}\right)(150)$. A meta-analysis including 1,210 patients with sepsis showed that different daily doses of intravenous ascorbate were associated with different results, and only a dose between 3-10 g/day resulted in decreased mortality, decreased need for vasopressor and mechanical ventilation, but not lower or higher doses (166).

In a prospective randomised placebo-controlled double blind trial - CITRIS-ALI - ascorbate $50 \mathrm{mg} / \mathrm{kg}$ or placebo was given q $6 \mathrm{~h}$ intravenously for $96 \mathrm{~h}$ to 167 patients with sepsis and ARDS; no significant difference was seen at $96 \mathrm{~h}$ in organ dysfunction scores (SOFA), inflammation marker CRP or thrombomodulin (for vascular integrity) (167). However, patients treated with vitamin $\mathrm{C}$ had a significant benefit in 28 -day mortality, transfer from ICU by hour 168 , number of ICU-free days by day 28 , and number of hospital-free days.

Hence in ascorbate deficiency, it is likely that when administered intravenously to hypotensive patients, ascorbate should be administered first, followed by a lower dose of arginine (ex $1500 \mathrm{mg}$ ascorbate in 100-200 $\mathrm{ml}$ normal saline followed by $1000 \mathrm{mg} \mathrm{L}$-arginine in $100 \mathrm{ml}$ saline administered at $1 \mathrm{ml} / \mathrm{min}$ ).

Other medication should be added depending on the clinical and laboratory signs: for the 'ground glass' image on imagistics, which signals presence of intra-alveolar- and intravascular emboli, especially when D-dimer is elevated: administration of anticoagulant, heparin or fractionated heparin; for signs of porphyria (spontaneous ecchymosis which do not change color) - chloroquine, amodiaquine, curcumin; for tachycardic, tachyarrhythmic patients amiodarone $400 \mathrm{mg}$ qd for a maximum 7 days; for all patients and especially with high cholesterol, simvastatin for asthma patients, Montelukast and/or fexofenadine or other lipophilic antihistaminic and antiinflammatory, preferably curcumin; for anti-inflammatory, analgesic actions - PPAR- $\alpha / \gamma$ agonists fenofibrate/pioglitasone or ABDH6 inhibitors KT185 and KT203 (which decrease macrophage activation and pain-inflicting CCXI-2 with allodynia); rabeprazole for preventing gastritis and for possible antiviral effects; methylprednisolone was shown to be of benefit in COVID-19 (4), and even with associated immune depression favoring viral replication, it can be considered for short-term in severely ill.

Practical measures - prevention and early interventions. A majority of SARS-CoV2 patients (85-90\%) have mild to moderate forms of disease, however $10-15 \%$ develop rapidly deteriorating forms with approximately half of those dying, and it is difficult to predict accurately the individual risk for developing severe disease besides advanced age and existing co-morbid conditions.

Unopposed or excessive viral replication is an important pathogenic mechanism through which the virus overwhelms the natural defenses of the body; besides a weakened immune response associated with chronic pathologies (cardiovascular, renal, hepatic, autoimmune and neoplasic), the virus has an advantage in tired or stressed individuals (with high cortisol and lactate/LDH levels) and by repeated exposure which increases the dose of the virus (doctors, nurses, medical personnel). Protective measures are very important for limiting exposure to the pathogen in vulnerable populations and also testing and treating early, as soon as possible after respiratory symptoms.

After infection and respiratory symptoms, prompt local treatment is very important: aerosol inhalation, nasal drops, throat sprays are very useful treatments. Water vapors hydrate the airway mucosa, increase the volume of ASL and help the natural clearance of the virus via mucus shedding. Adding to the inhaled vapors natural antimicrobials such as rosemary, basil, tea tree, mint, eucalyptus, thyme, onion, in fresh or dry form; throat or nasal sprays with propolis, argentum, basil, thyme, cumin will also help viral inactivation and decrease inflammation.

We propose arginine-ascorbate as the mainstay of antiviral treatment for SARS-CoV2 and other coronaviruses, administered from the initial signs of infection until its resolution.

As much as NSAIDs (non-steroidal antiinflammatory drugs) are not recommended (aspirin, ibuprofen, naproxene and indomethacin), possibly because of concomitant inhibition of PGD2, known to be elevated in elderly patients, and further elevated by SARS-CoV infection and in more severe forms of COVID-19 (73); however PGD2 has protective, anti-inflammatory actions, and blocking cyclooxygenase (COX) also inhibits PGD2, which further imbalances an already malfunctioning immune response.

Interestingly, NSAID-mediated curcumin (also a main protease inhibitor) is useful for alleviating inflammation and pain, and if rhinitis and conjunctive inflammation are present, an antihistaminic can be of help (fexofenadine also inhibits the main COVID-19 protease). We have successfully used the curcumin/antihistaminic combination for pain of various types from sore throat to allodynia, in patients with allergies, increased PGD2, rheumatoid arthritis, and also for porphyria. Patients who cannot tolerate curcumin may use instead extracts of Boswellia serrata (400 mg tid) as anti-inflammatory and analgesic; artemisinin can be a good substitute for chloroquine or amiodarone in patients with prolonged QT interval, COPD or lung fibrosis.

Risk evaluation of $\mathrm{CoV}$ infected patients. Assessing the risk for progression to severe forms early on during $\mathrm{CoV}$ infection is important for prompt individual treatment and medical resource management, and also to avoid imposing restriction on the whole population, knowing that $90 \%$ of infections are asymptomatic or can be treated outside hospital; this may allow shifting isolation measures from whole populations to truly at-risk populations (168).

A two-pronged strategy of risk evaluation can be employed based on age and exposure risk: in younger individuals ( $\leq 55$ years old) a specific panel for genetic risk factors which predispose to fatal $\mathrm{CoV}$ infections (rs78142040, rs9605146, rs3848719; NAMPT - 1001G allele, POPDC3, PDE4B, ABCC1, TNFRS11 and DD genotype of ACE) may be more useful, especially in individuals with potential increased exposure to the virus (eg., healthcare professionals). However, in patients most at-risk - elderly and with chronic co-morbidities, 
evaluation with different testing panels can reasonably assess their risk for severe COVID19, starting with the evaluation of oxidative/peroxisomal status (catalase, malondialdehyde), inflammation - CRP, fibrinogen - and metabolism - bicarbonate, HgbA1c, lipid profile, and immune balance - PGD2 and serum protein electrophoresis - for asymptomatic patients, and adding for symptomatic patients the $\mathrm{CD} 3^{+}, \mathrm{CD} 4^{+}, \mathrm{CD} 8^{+}$and NK counts (predictors of need for intensive care), LD1 isoensyme, which were good predictors for intensive care during the SARS epidemic (169); for hyper-inflammatory status also useful are markers of neutrophil activation - MMP-9, LTB4, ferritin, CXCl-2 (106).

Another approach to risk evaluation of severe COV infection is measuring the high-sensitivity cardiac troponin (hs-cTnT), shown with data from the ARIC study to be a marker for end-organ damage in patients with chronic pathologies (170); elevated troponin levels were also seen in some COVID-19 patients (9).

Our efforts as front-line defenders against this invisible foe, SARS-CoV, and possible others to come, are essential not only from a medical perspective but also towards fully regaining our individual and societal freedoms; through risk evaluation and prompt, effective treatments the burden of disease can be greatly diminished for both individuals and whole populations.

\section{Acknowledgements}

The present study is dedicated to the memory of Mihail Coculescu.

\section{Funding}

No funding was received.

\section{Availability of data and materials}

Not applicable.

\section{Authors' contributions}

FS conceived and designed the study, tables and figures and drafted the manuscript. BNI, GZP, DAS, AT, MDC and SK performed analysis of data, researched the literature and critically revised the article for important intellectual content. All authors read and approved the final manuscript.

\section{Ethics approval and consent to participate}

Not applicable.

\section{Patient consent for publication}

Not applicable.

\section{Competing interests}

DAS is the Editor-in-Chief for the journal, but had no personal involvement in the reviewing process, or any influence in terms of adjudicating on the final decision, for this article. All the other authors declare that they have no competing interests.

\section{References}

1. Wu Z and McGoogan JM: Characteristics of and important lessons from the coronavirus disease 2019 (COVID-19) outbreak in China: Summary of a report of 72314 cases from the Chinese Center for Disease Control and Prevention. JAMA 323: 1239-1242, 2020.

2. Yang X, Yu Y, Xu J, Shu H, Xia J, Liu H, Wu Y, Zhang L, Yu Z, Fang M, et al: Clinical course and outcomes of critically ill patients with SARS-CoV-2 pneumonia in Wuhan, China: A single-centered, retrospective, observational study. Lancet Respir Med 8: 475-481, 2020.

3. Li JY, You Z, Wang Q, Zhou ZJ, Qiu Y, Luo R and Ge XY: The epidemic of 2019-novel-coronavirus (2019-nCoV) pneumonia and insights for emerging infectious diseases in the future. Microbes Infect 22: 80-85, 2020.

4. Wu C, Chen X, Cai Y Xia J, Zhou X, Xu S, Huang H, Li Zhang L, Zhou X, Du C, et al: Risk factors associated with acute respiratory distress syndrome and death in patients with coronavirus disease 2019 pneumonia in Wuhan, China. JAMA Intern Med: Mar. 13, 20202020 (Epub ahead of print). doi:10.1001/jamainternmed.2020.0994.

5. Grasselli G, Pesenti A and Cecconi M: Critical care utilization for the COVID-19 outbreak in Lombardy, Italy: Early experience and forecast during an emergency response. JAMA 323: 1545, 2020.

6. Goumenou M, Sarigiannis D, Tsatsakis A, Anesti O, Docea AO, Petrakis D, Tsoukalas D, Kostoff R, Rakitskii V, Spandidos DA, et al: COVID-19 in Northern Italy: An integrative overview of factors possibly influencing the sharp increase of the outbreak (Review). Mol Med Rep 22: 20-32, 2020.

7. Petrakis D, Margină D, Tsarouhas K, Tekos F, Stan M, Nikitovic D, Kouretas D, Spandidos DA and Tsatsakis A: Obesity - a risk factor for increased COVID-19 prevalence, severity and lethality (Review). Mol Med Rep 22: 9-19, 2020.

8. Docea AO, Tsatsakis A, Albulescu D, Cristea O, Zlatian O, Vinceti M, Moschos SA, Tsoukalas D, Goumenou M, Drakoulis N, et al: A new threat from an old enemy: Re-emergence of coronavirus (Review). Int J Mol Med 45: 1631-1643, 2020

9. Kluge S, Janssens U, Welte T, Weber-Carstens S, Marx G and Karagiannidis C: German recommendations for critically ill patients with COVID-19. Med Klin Intensivmed Notfmed: Apr 14, 2020 (Epub ahead of print). doi: 10.1007/s00063-020-00689-w.

10. Bhatraju PK, Ghassemieh BJ, Nichols M, Kim R, Jerome KR, Nalla AK, Greninger AL, Pipavath S, Wurfel MM, Evans L, et al: Covid-19 in critically ill patients in the Seattle region - case series. N Engl J Med 382: 2012-2022, 2020.

11. Farsalinos K, Niaura R, Le Houezec J, Barbouni A, Tsatsakis A, Kouretas D, Vantarakis A and Poulas K: Editorial: Nicotine and SARS-CoV-2: COVID-19 may be a disease of the nicotinic cholinergic system. Toxicol Rep 7: 658-663, 2020.

12. Calfee CS, Delucchi K, Parsons PE, Thompson BT, Ware LB and Matthay MA; NHLBI ARDS Network: Subphenotypes in acute respiratory distress syndrome: Latent class analysis of data from two randomised controlled trials. Lancet Respir Med 2: 611-620, 2014.

13. Wilson JG and Calfee CS: ARDS subphenotypes: Understanding a heterogeneous syndrome. Crit Care 24: 102, 2020.

14. Famous KR, Delucchi K, Ware LB, Kangelaris KN, Liu KD, Thompson BT and Calfee CS; ARDS Network: Acute respiratory distress syndrome subphenotypes respond differently to randomized fluid management strategy. Am J Respir Crit Care Med 195: 331-338, 2017.

15. Calfee CS, Delucchi KL, Sinha P, Matthay MA, Hackett J, Shankar-Hari M, McDowell C, Laffey JG, O'Kane CM, McAuley DF, et al; Irish Critical Care Trials Group: Acute respiratory distress syndrome subphenotypes and differential response to simvastatin: Secondary analysis of a randomised controlled trial. Lancet Respir Med 6: 691-698, 2018.

16. Sinha P, Delucchi KL, Thompson BT, McAuley DF, Matthay MA and Calfee CS; NHLBI ARDS Network: Latent class analysis of ARDS subphenotypes: A secondary analysis of the statins for acutely injured lungs from sepsis (SAILS) study. Intensive Care Med 44: 1859-1869, 2018.

17. de Wilde AH, Jochmans D, Posthuma CC, Zevenhoven-Dobbe JC, van Nieuwkoop S, Bestebroer TM, van den Hoogen BG, Neyts J and Snijder EJ: Screening of an FDA-approved compound library identifies four small-molecule inhibitors of Middle East respiratory syndrome coronavirus replication in cell culture. Antimicrob Agents Chemother 58: 4875-4884, 2014. 
18. Cascella M, Rajnik M, Cuomo A, Dulebohn SC and Di Napoli R Features, evaluation and treatment coronavirus (COVID-19). In: StatPearls [Internet]. Treasure Island (FL): StatPearls Publishing; 2020 Jan-. PMID: 32150360. https://www.ncbi.nlm. nih.gov/books/NBK554776.

19. Neagu M, Bostan M and Constantin C: Protein microarray technology: Assisting personalized medicine in oncology (Review) World Acad Sci J 1: 113-124, 2019.

20. Levitt JE and Rogers AJ: Proteomic study of acute respiratory distress syndrome: Current knowledge and implications for drug development. Expert Rev Proteomics 13: 457-469, 2016.

21. Meyer NJ, Reilly JP, Anderson BJ, Palakshappa JA, Jones TK, Dunn TG, Shashaty MGS, Feng R, Christie JD and Opal SM: Mortality benefit of recombinant human interleukin-1 receptor antagonist for sepsis varies by initial interleukin-1 receptor antagonist plasma concentration. Crit Care Med 46: 21-28, 2018.

22. Brandes M, Klauschen F, Kuchen S and Germain RN: A systems analysis identifies a feed forward inflammatory circuit leading to lethal influenza infection. Cell 154: 197-212, 2013.

23. Bowen JR, Ferris MT and Suthar MS: Systems biology: A tool for charting the antiviral landscape. Virus Res 218: 2-9, 2016.

24. Kindler E, Thiel V and Weber F: Interaction of SARS and MERS coronaviruses with the antiviral interferon response. Adv Virus Res 96: 219-243, 2016.

25. Channappanavar R, Fehr AR, Vijay R, Mack M, Zhao J, Meyerholz DK and Perlman S: Dysregulated type I interferon and inflammatory monocyte-macrophage responses cause lethal pneumonia in SARS-CoV-infected mice. Cell Host Microbe 19: 181-193, 2016

26. Baughman RP, Gunther KL, Rashkin MC, Keeton DA and Pattishall EN: Changes in the inflammatory response of the lung during acute respiratory distress syndrome: Prognostic indicators. Am J Respir Crit Care Med 154: 76-81, 1996.

27. Kast RE: Dapsone as treatment adjunct in ARDS. Exp Lung Res 46: 157-161, 2020

28. Coleman MD, Rhodes LE, Scott AK, Verbov JL, Friedmann PS, Breckenridge AM and Park BK: The use of cimetidine to reduce dapsone-dependent methaemoglobinaemia in dermatitis herpetiformis patients. Br J Clin Pharmacol 34: 244-249, 1992.

29. Meo SA, Alhowikan AM, Al-Khlaiwi T, Meo IM, Halepoto DM, Iqbal M, Usmani AM, Hajjar W and Ahmed N: Novel coronavirus 2019-nCoV: Prevalence, biological and clinical characteristics comparison with SARS-CoV and MERS-CoV. Eur Rev Med Pharmacol Sci 24: 2012-2019, 2020.

30. Nitulescu GM, Paunescu H, Moschos SA, Petrakis D, Nitulescu G, Ion GND, Spandidos DA, Nikolouzakis TK Drakoulis $\mathrm{N}$ and Tsatsakis A: Comprehensive analysis of drugs to treat SARS-CoV-2 infection: Mechanistic insights into current COVID-19 therapies (Review). Int J Mol Med 46: 467-488, 2020

31. Tsatsakis A, Petrakis D, Nikolouzakis TK, Docea AO, Calina D, Vinceti M, Goumenou M, Kostoff RN, Mamoulakis C, Aschner M, et al: COVID-19, an opportunity to reevaluate the correlation between long-term effects of anthropogenic pollutants on viral epidemic/pandemic events and prevalence. Food Chem Toxicol 141: 111418, 2020.

32. Lu R, Zhao X, Li J, Niu P, Yang B, Wu H, Wang W, Song H, Huang B, Zhu N, et al: Genomic characterisation and epidemiology of 2019 novel coronavirus: Implications for virus origins and receptor binding. Lancet 395: 565-574, 2020.

33. Wu A, Peng Y, Huang B, Ding X, Wang X, Niu P, Meng J, Zhu Z, Zhang Z, Wang J, et al: Genome composition and divergence of the novel coronavirus $(2019-\mathrm{nCoV})$ originating in China. Cell Host Microbe 27: 325-328, 2020

34. Sah R, Rodriguez-Morales AJ, Jha R, Chu DKW, Gu H, Peiris M, Bastola A, Lal BK, Ojha HC, Rabaan AA, et al Complete genome sequence of a 2019 novel coronavirus (SARS-CoV-2) strain isolated in Nepal. Microbiol Resour Announc 9: 9, 2020.

35. Cui J, Li F and Shi ZL: Origin and evolution of pathogenic coronaviruses. Nat Rev Microbiol 17: 181-192, 2019.

36. Xu J, Zhao S, Teng T, Abdalla AE, Zhu W, Xie L, Wang Y and Guo X: Systematic comparison of two animal-to-human transmitted human coronaviruses: SARS-CoV-2 and SARS-CoV. Viruses 12: 12, 2020.

37. Liu W and Li H: COVID-19: Attacks the 1-beta chain of hemoglobin and captures the porphyrin to inhibit human heme metabolism. ChemRxiv 2020. Preprint. https://doi. org/10.26434/chemrxiv.11938173.v8.
38. Yang Q, Bai S-Y, Li L-F, Li S, Zhang Y, Munir M and Qiu H-J: Human hemoglobin subunit beta functions as a pleiotropic regulator of RIG-I/MDA5-mediated antiviral innate immune responses. J Virol 93: 93, 2019.

39. $\mathrm{Li} \mathrm{T}, \mathrm{Lu} \mathrm{H}$ and Zhang W: Clinical observation and management of COVID-19 patients. Emerg Microbes Infect 9: 687-690, 2020.

40. Wan Y, Shang J, Graham R, Baric RS and Li F: Receptor recognition by the novel coronavirus from Wuhan: An analysis based on decade-long structural studies of SARS coronavirus. J Virol 94: 94, 2020.

41. Xie M and Chen Q: Insight into 2019 novel coronavirus - An updated interim review and lessons from SARS-CoV and MERS-CoV. Int J Infect Dis 94: 119-124, 2020.

42. Hwang SS, Lim J, Yu Z, Kong P, Sefik E, Xu H, Harman CCD, Kim LK, Lee GR, Li HB and Flavell RA: mRNA destabilization by BTG1 and BTG2 maintains T cell quiescence. Science 367: 1255-1260, 2020.

43. Coutard B, Valle C, de Lamballerie X, Canard B, Seidah NG and Decroly E: The spike glycoprotein of the new coronavirus 2019-nCoV contains a furin-like cleavage site absent in $\mathrm{CoV}$ of the same clade. Antiviral Res 176: 104742, 2020.

44. Kawase M, Shirato K, van der Hoek L, Taguchi F and Matsuyama S: Simultaneous treatment of human bronchial epithelial cells with serine and cysteine protease inhibitors prevents severe acute respiratory syndrome coronavirus entry. J Virol 86: 6537-6545, 2012.

45. Hoffmann M, Kleine-Weber H, Schroeder S, Krüger N, Herrler T, Erichsen S, Schiergens TS, Herrler G, Wu NH, Nitsche A, et al: SARS-CoV-2 cell entry depends on ACE2 and TMPRSS2 and is blocked by a clinically proven protease inhibitor. Cell 181: 271-280.e8, 2020.

46. Xia S, Liu M, Wang C, Xu W, Lan Q, Feng S, Qi F, Bao L, Du L, Liu S, et al: Inhibition of SARS-CoV-2 (previously 2019-nCoV) infection by a highly potent pan-coronavirus fusion inhibitor targeting its spike protein that harbors a high capacity to mediate membrane fusion. Cell Res 30: 343-355, 2020.

47. Millet JK and Whittaker GR: Physiological and molecular triggers for SARS-CoV membrane fusion and entry into host cells. Virology 517: 3-8, 2018.

48. Totura AL and Bavari S: Broad-spectrum coronavirus antiviral drug discovery. Expert Opin Drug Discov 14: 397-412, 2019.

49. Amatngalim GD and Hiemstra PS: Airway epithelial cell function and respiratory host defense in chronic obstructive pulmonary disease. Chin Med J (Engl) 131: 1099-1107, 2018.

50. Chiang JJ, Davis ME and Gack MU: Regulation of RIG-I-like receptor signaling by host and viral proteins. Cytokine Growth Factor Rev 25: 491-505, 2014

51. Schneider WM, Chevillotte MD and Rice CM: Interferonstimulated genes: A complex web of host defenses. Annu Rev Immunol 32: 513-545, 2014.

52. Takeuchi $\mathrm{O}$ and Akira S: Pattern recognition receptors and inflammation. Cell 140: 805-820, 2010.

53. Dixit E, Boulant S, Zhang Y, Lee AS, Odendall C, Shum B, Hacohen N, Chen ZJ, Whelan SP, Fransen M, et al: Peroxisomes are signaling platforms for antiviral innate immunity. Cell 141: 668-681, 2010

54. Kindler E, Gil-Cruz C, Spanier J, Li Y, Wilhelm J, Rabouw HH, Züst R, Hwang M, V'kovski P, Stalder H, et al: Early endonuclease-mediated evasion of RNA sensing ensures efficient coronavirus replication. PLoS Pathog 13: e1006195, 2017.

55. Cao W, Bao C, Padalko E and Lowenstein CJ: Acetylation of mitogen-activated protein kinase phosphatase-1 inhibits Toll-like receptor signaling. J Exp Med 205: 1491-1503, 2008.

56. Zhou Y, He C, Wang L and Ge B: Post-translational regulation of antiviral innate signaling. Eur J Immunol 47: 1414-1426, 2017.

57. Quicke KM, Diamond MS and Suthar MS: Negative regulators of the RIG-I-like receptor signaling pathway. Eur J Immunol 47: 615-628, 2017.

58. Vincent MJ, Bergeron E, Benjannet S, Erickson BR, Rollin PE, Ksiazek TG, Seidah NG and Nichol ST: Chloroquine is a potent inhibitor of SARS coronavirus infection and spread. Virol J 2: 69, 2005.

59. Samarth S and McGregor K: Energetics based modeling of hydroxychloroquine and azithromycin binding to the SARS-CoV-2 spike (S)protein - ACE2 complex. ChemRxiv, 2020. Preprint. https://doi.org/10.26434/chemrxiv.12015792.v2.

60. Arya R, Das A, Prashar V and Kumar M: Potential inhibitors against papain-like protease of novel coronavirus (SARS-CoV-2) from FDA approved drugs. ChemrxivOrg: 1-8, 2020. doi: $10.26434 /$ chemrxiv.11860011. 
61. Dyall J, Gross R, Kindrachuk J, Johnson RF, Olinger GG Jr, Hensley LE, Frieman MB and Jahrling PB: Middle East respiratory syndrome and severe acute respiratory syndrome: Current therapeutic options and potential targets for novel therapies. Drugs 77: 1935-1966, 2017.

62. Choudhary S, Malik YS and Tomar S: Identification of SARS-CoV-2 cell entry inhibitors by drug repurposing using in silico structure-based virtual screening approach. ChemRxiv, 2020. doi: $10.26434 /$ chemrxiv.12005988.

63. Farag A, Wang P, Boys IN, Eitson J, Ohlson MB, Fan W, McDougal MB, Ahmed M and Schoggins JW: Identification of atovaquone, quabain and mebendazole as FDA approved drugs Tar-geting SARS-CoV-2 (Version 4)., 2020. ChemRxiv. Preprint. https://doi.org/10.26434/chemrxiv.12003930.v4.

64. Navan C: Possible Drug Candidates for COVID-19. ChemRxiv, 2020. Preprint. https://doi.org/10.26434/chemrxiv.11985231.v1.

65. Bag A and Bag A: Treatment of COVID-19 patients: Justicia adhatoda leaves extract is a strong remedy for COVID-19 - Case report analysis and docking based study. ChemRxiv, 2020. Preprint. https://doi.org/10.26434/chemrxiv.12038604.v1.

66. Coleman CM, Sisk JM, Mingo RM, Nelson EA, White JM and Frieman MB: Abelson kinase inhibitors are potent inhibitors of severe acute respiratory syndrome coronavirus and Middle East respiratory syndrome coronavirus fusion. J Virol 90: 8924-8933, 2016.

67. Sisk JM, Frieman MB and Machamer CE: Coronavirus $\mathrm{S}$ protein-induced fusion is blocked prior to hemifusion by $\mathrm{Abl}$ kinase inhibitors. J Gen Virol 99: 619-630, 2018.

68. Salim B and Noureddine M: Identification of compounds from Nigella sativa as new potential inhibitors of 2019 novel corona virus (Covid-19): Molecular docking study. ChemRxiv, 2020. Preprint. https://doi.org/10.26434/chemrxiv.12055716.v1.

69. Pendyala B and Patras A: In silico screening of food bioactive compoundstopredictpotentialinhibitors ofCOVID-19mainprotease (Mpro) and RNA-dependent RNA polymerase (RdRp). ChemRxiv. Preprint. https://doi.org/10.26434/chemrxiv.12051927.v2.

70. Mohammadi N: Inhibitory effect of eight secondary metabolites from conventional medicinal plants on COVID-19 virus protease by molecular docking analysis. ChemRxiv, 2020. Preprint. https://doi.org/10.26434/chemrxiv.11987475.v1.

71. Bosch BJ, Martina BEE, Van Der Zee R, Lepault J, Haijema BJ, Versluis C, Heck AJ, De Groot R, Osterhaus AD and Rottier PJ: Severe acute respiratory syndrome coronavirus (SARS-CoV) infection inhibition using spike protein heptad repeat-derived peptides. Proc Natl Acad Sci USA 101: 8455-8460, 2004

72. Yang Z-Y, Huang Y, Ganesh L, Leung K, Kong WP, Schwartz O, Subbarao K and Nabel GJ: pH-dependent entry of severe acute respiratory syndrome coronavirus is mediated by the spike glycoprotein and enhanced by dendritic cell transfer through DC-SIGN. J Virol 78: 5642-5650, 2004

73. Zhao J, Wohlford-Lenane C, Zhao J, Fleming E, Lane TE, McCray PB Jr and Perlman S: Intranasal treatment with poly $(\mathrm{I} \cdot \mathrm{C})$ protects aged mice from lethal respiratory virus infections. J Virol 86: 11416-11424, 2012.

74. Mian MF, Ahmed AN, Rad M, Babaian A, Bowdish D and Ashkar AA: Length of dsRNA (poly I:C) drives distinct innate immune responses, depending on the cell type. J Leukoc Biol 94 1025-1036, 2013

75. Cameron A, Appel J, Houghten RA and Lindberg I: Polyarginines are potent furin inhibitors. J Biol Chem 275: 36741-36749, 2000.

76. Channappanavar R, Lu L, Xia S, Du L, Meyerholz DK, Perlman S and Jiang S: Protective effect of intranasal regimens containing peptidic Middle East respiratory syndrome coronavirus fusion inhibitor against MERS-CoV infection. - Abstract - Europe PMC. https://europepmc.org/article/med/26164863.

77. Zhou H, Zhao J and Perlman S: Autocrine interferon priming in macrophages but not dendritic cells results in enhanced cytokine and chemokine production after coronavirus infection. MBio 1: $1,2010$.

78. Iwasaki A and Medzhitov R: Regulation of adaptive immunity by the innate immune system. Science 327: 291-295, 2010.

79. Sainz B Jr, Mossel EC, Peters CJ and Garry RF: Interferon-beta and interferon-gamma synergistically inhibit the replication of severe acute respiratory syndrome-associated coronavirus (SARS-CoV). Virology 329: 11-17, 2004.

80. Der SD, Zhou A, Williams BRG and Silverman RH: Identification of genes differentially regulated by interferon $\alpha, \beta$, or $\gamma$ using oligonucleotide arrays. Proc Natl Acad Sci USA 95: 15623-15628, 1998.
81. Bauman DR, Bitmansour AD, McDonald JG, Thompson BM, Liang G and Russell DW: 25-Hydroxycholesterol secreted by macrophages in response to Toll-like receptor activation suppresses immunoglobulin A production. Proc Natl Acad Sci USA 106: 16764-16769, 2009.

82. Mantovani A, Biswas SK, Galdiero MR, Sica A and Locati M: Macrophage plasticity and polarization in tissue repair and remodelling. J Pathol 229: 176-185, 2013.

83. Gralinski LE and Baric RS: Molecular pathology of emerging coronavirus infections. J Pathol 235: 185-195, 2015.

84. de Wilde AH, Wannee KF, Scholte FEM, Goeman JJ, Ten Dijke P, Snijder EJ, Kikkert M and van Hemert MJ: A kinome-wide small interfering RNA screen identifies proviral and antiviral host factors in severe acute respiratory syndrome coronavirus replication, including double-stranded RNA-activated protein kinase and early secretory pathway proteins. J Virol 89: 8318-8333, 2015.

85. Newton DA, Rao KMK, Dluhy RA and Baatz JE: Hemoglobin is expressed by alveolar epithelial cells. J Biol Chem 281: 5668-5676, 2006

86. Aldajani WA, Salazar F, Sewell HF, Knox A and Ghaemmaghami AM: Expression and regulation of immunemodulatory enzyme indoleamine 2,3-dioxygenase (IDO) by human airway epithelial cells and its effect on T cell activation. Oncotarget 7: 57606-57617, 2016.

87. Mondanelli G, Bianchi R, Pallotta MT, Orabona C, Albini E, Iacono A, Belladonna ML, Vacca C, Fallarino F, Macchiarulo A, et al: A relay pathway between arginine and tryptophan metabolism confers immunosuppressive properties on dendritic cells. Immunity 46: 233-244, 2017.

88. Nordgren $\mathrm{M}$ and Fransen M: Peroxisomal metabolism and oxidative stress. Biochimie 98: 56-62, 2014.

89. Titorenko VI and Terlecky SR: Peroxisome metabolism and cellular aging. Traffic 12: 252-259, 2011.

90. Xu Z, Lodge R, Power C, Cohen EA and Hobman TC: The HIV-1 accessory protein vpu downregulates peroxisome biogenesis. MBio 11: 11, 2020.

91.Zheng $\mathrm{C}$ and Su C: Herpes simplex virus 1 infection dampens the immediate early antiviral innate immunity signaling from peroxisomes by tegument protein VP16. Virol J 14: 35, 2017.

92. Ferreira AR, Marques M and Ribeiro D: Peroxisomes and innate immunity: Antiviral response and beyond. Int J Mol Sci 20: 20 , 2019.

93. Skalny AV, Rink L, Ajsuvakova OP, Aschner M, Gritsenko VA, Alekseenko SI, Svistunov AA, Petrakis D, Spandidos DA, Aaseth J, et al: Zinc and respiratory tract infections: Perspectives for COVID-19 (Review). Int J Mol Med 46: 17-26, 2020.

94. Gastaminza P, Whitten-Bauer C and Chisari FV: Unbiased probing of the entire hepatitis $\mathrm{C}$ virus life cycle identifies clinical compounds that target multiple aspects of the infection. Proc Natl Acad Sci USA 107: 291-296, 2010.

95. Simmons G, Gosalia DN, Rennekamp AJ, Reeves JD, Diamond SL and Bates P: Inhibitors of cathepsin L prevent severe acute respiratory syndrome coronavirus entry. Proc Natl Acad Sci USA 102: 11876-11881, 2005.

96. Blanchard E, Belouzard S, Goueslain L, Wakita T, Dubuisson J, Wychowski C and Rouillé Y: Hepatitis C virus entry depends on clathrin-mediated endocytosis. J Virol 80: 6964-6972, 2006.

97. Trevani AS, Andonegui G, Giordano M, López DH, Gamberale R, Minucci F and Geffner JR: Extracellular acidification induces human neutrophil activation. J Immunol 162. 4849-4857, 1999.

98. Rotstein OD, Fiegel VD, Simmons RL and Knighton DR: The deleterious effect of reduced $\mathrm{pH}$ and hypoxia on neutrophil migration in vitro. J Surg Res 45: 298-303, 1988

99. Lardner A: The effects of extracellular $\mathrm{pH}$ on immune function. J Leukoc Biol 69: 522-530, 2001.

100. Simchowitz L: Intracellular $\mathrm{pH}$ modulates the generation of superoxide radicals by human neutrophils. J Clin Invest 76: 1079-1089, 1985.

101. Severin T, Müller B, Giese G, Uhl B, Wolf B, Hauschildt S and Kreutz W: pH-dependent LAK cell cytotoxicity. Tumour Biol 15: 304-310, 1994.

102. Kellum JA, Song M and Li J: Science review: extracellular acidosis and the immune response: clinical and physiologic implications. Crit Care 8: 331-336, 2004.

103. Hamdullah KS, Tanzila A, Zainab Sher M, Iqra A and Mohtasheemul H: $\mathrm{pH}$ dependent differential binding behavior of protease inhibitor molecular drugs for SARS-COV-2. ChemRxiv, 2020. Preprint. https://doi.org/10.26434/chemrxiv.12009018.v1. 
104.Leneva IA, Russell RJ, Boriskin YS and Hay AJ: Characteristics of arbidol-resistant mutants of influenza virus: Implications for the mechanism of anti-influenza action of arbidol. Antiviral Res 81: 132-140, 2009.

105. Bhargava M, Becker TL, Viken KJ, Jagtap PD, Dey S, Steinbach MS, Wu B, Kumar V, Bitterman PB, Ingbar DH, et al: Proteomic profiles in acute respiratory distress syndrome differentiates survivors from non-survivors. PLoS One 9: e109713, 2014.

106. Shortt K, Chaudhary S, Grigoryev D, Heruth DP, Venkitachalam L, Zhang LQ and Ye SQ: Identification of novel single nucleotide polymorphisms associated with acute respiratory distress syndrome by exome-seq. PLoS One 9: e111953, 2014.

107. Tejera P, Meyer NJ, Chen F, Feng R, Zhao Y, O'Mahony DS, Li L, Sheu CC, Zhai R, Wang Z, et al: Distinct and replicable genetic risk factors for acute respiratory distress syndrome of pulmonary or extrapulmonary origin. J Med Genet 49: 671-680, 2012.

108. Lynn H, Sun X, Casanova N, Gonzales-Garay M, Bime C and Garcia JGN: Genomic and genetic approaches to deciphering acute respiratory distress syndrome risk and mortality. Antioxid Redox Signal 31: 1027-1052, 2019.

109. Marshall RP, Webb S, Bellingan GJ, Montgomery HE, Chaudhari B, McAnulty RJ, Humphries SE, Hill MR and Laurent GJ: Angiotensin converting enzyme insertion/deletion polymorphism is associated with susceptibility and outcome in acute respiratory distress syndrome. Am J Respir Crit Care Med 166: 646-650, 2002.

110. Itoyama S, Keicho N, Quy T, Phi NC, Long HT, Ha LD, Ban VV, Ohashi J, Hijikata M, Matsushita I, et al: ACE1 polymorphism and progression of SARS. Biochem Biophys Res Commun 323: $1124-1129,2004$.

111. Chan KCA, Tang NLS, Hui DSC, Chung GT, Wu AK, Chim SS, Chiu RW, Lee N, Choi KW, Sung YM, et al: Absence of association between angiotensin converting enzyme polymorphism and development of adult respiratory distress syndrome in patients with severe acute respiratory syndrome: A case control study. BMC Infect Dis 5: 26, 2005.

112. Fourrier F, Chopin C, Wallaert B, Wattre P, Mangalaboyi J, Durocher A, Dubois D and Wattel F: Angiotensin-converting enzyme in human adult respiratory distress syndrome. Chest 83 : 593-597, 1983

113. Imai Y, Kuba K, Rao S, Huan Y, Guo F, Guan B, Yang P, Sarao R, Wada T, Leong-Poi H, et al: Angiotensin-converting enzyme 2 protects from severe acute lung failure. Nature 436: $112-116,2005$

114. Arndt PG, Young SK, Poch KR, Nick JA, Falk S, Schrier RW and Worthen GS: Systemic inhibition of the angiotensin-converting enzyme limits lipopolysaccharide-induced lung neutrophil recruitment through both bradykinin and angiotensin II-regulated pathways. J Immunol 177: 7233-7241, 2006.

115. Kim J, Choi SM, Lee J, Park YS, Lee CH, Yim JJ, Yoo CG, Kim YW, Han SK and Lee SM: Effect of renin-angiotensin system blockage in patients with acute respiratory distress syndrome: A retrospective case control study. Korean J Crit Care Med 32: 154-163, 2017.

116. Wevers BA and van der Hoek L: Renin-angiotensin system in human coronavirus pathogenesis. Future Virol 5: 145-161, 2010.

117. Chappell MC and Zayadneh EM Al: Angiotensin-(1-7) and the regulation of anti-fibrotic signaling pathways. J Cell Signal 2 : $134,2017$.

118. El-Hashim AZ, Renno WM, Raghupathy R, Abduo HT, Akhtar S and Benter IF: Angiotensin-(1-7) inhibits allergic inflammation, via the MAS1 receptor, through suppression of ERK1/2- and NF- $\kappa B$-dependent pathways. Br J Pharmacol 166: 1964-1976, 2012

119. Manolis AJ, Marketou ME, Gavras I and Gavras H: Cardioprotective properties of bradykinin: Role of the $\mathrm{B}(2)$ receptor. Hypertens Res 33: 772-777, 2010.

120. Adam A, Cugno M, Molinaro G, Perez M, Lepage Y and Agostoni A: Aminopeptidase P in individuals with a history of angio-oedema on ACE inhibitors. Lancet 359: 2088-2089, 2002 .

121. Yeager CL, Ashmun RA, Williams RK, Cardellichio CB, Shapiro LH, Look AT and Holmes KV: Human aminopeptidase $\mathrm{N}$ is a receptor for human coronavirus 229E. Nature 357: 420-422, 1992.

122. Morris SM Jr: Arginine: Master and commander in innate immune responses. Sci Signal 3: pe27, 2010.
123. Keyaerts E, Vijgen L, Chen L, Maes P, Hedenstierna G and Van Ranst M: Inhibition of SARS-coronavirus infection in vitro by $\mathrm{S}$-nitroso-N- acetylpenicillamine, a nitric oxide donor compound. In: International Journal of Infectious Diseases. Int J Infect Dis 8: 223-226, 2004.

124.Akerström S, Mousavi-Jazi M, Klingström J, Leijon M, Lundkvist A and Mirazimi A: Nitric oxide inhibits the replication cycle of severe acute respiratory syndrome coronavirus. J Virol 79: 1966-1969, 2005.

125. Cinatl J, Morgenstern B, Bauer G, Chandra P, Rabenau H and Doerr HW: Treatment of SARS with human interferons. Lancet 362: 293-294, 2003.

126.Karupiah G, Xie OW, Buller RML, Nathan C, Duarte C and MacMicking JD: Inhibition of viral replication by interferon- $\gamma$-induced nitric oxide synthase. Science 261: 1445-1448, 1993.

127. Burrack KS and Morrison TE: The role of myeloid cell activation and arginine metabolism in the pathogenesis of virus-induced diseases. Front Immunol 5: 428, 2014

128. Munder M, Schneider H, Luckner C, Giese T, Langhans CD, Fuentes JM, Kropf P, Mueller I, Kolb A, Modolell M, et al: Suppression of T-cell functions by human granulocyte arginase. Blood 108: 1627-1634, 2006.

129. Racké K and Warnken M: L-Arginine metabolic pathways. The Open Nitric Oxide Journal 2: 9-19, 2010. https://benthamopen. com/contents/pdf/TONOJ/TONOJ-2-9.pdf.

130. Gournas C, Papageorgiou I and Diallinas G: The nucleobaseascorbate transporter (NAT) family: Genomics, evolution, structure-function relationships and physiological role. Mol Biosyst 4: 404-416, 2008.

131. Carr AC and Maggini S: Vitamin C and immune function. Nutrients 9: 9, 2017.

132. García-Bailo B, Roke K, Mutch DM, El-Sohemy A and Badawi A: Association between circulating ascorbic acid, $\alpha$-tocopherol, 25-hydroxyvitamin $\mathrm{D}$, and plasma cytokine concentrations in young adults: A cross-sectional study. Nutr Metab (Lond) 9: 102, 2012.

133. Wu G and Morris SM Jr: Arginine metabolism: Nitric oxide and beyond. Biochem J 336: 1-17, 1998.

134. Scheit K and Bauer G: Synergistic effects between catalase inhibitors and modulators of nitric oxide metabolism on tumor cell apoptosis. Anticancer Res 34: 5337-5350, 2014.

135. Thomas SR, Mohr D and Stocker R: Nitric oxide inhibits indoleamine 2,3-dioxygenase activity in interferon-gamma primed mononuclear phagocytes. J Biol Chem 269: 14457-14464, 1994.

136. Shi HP, Efron DT, Most D, Tantry US and Barbul A: Supplemental dietary arginine enhances wound healing in normal but not inducible nitric oxide synthase knockout mice. Surgery 128: 374-378, 2000.

137. Rodriguez PC, Quiceno DG and Ochoa AC: L-arginine availability regulates T-lymphocyte cell-cycle progression. Blood 109: 1568-1573, 2007.

138. Ochoa JB, Strange J, Kearney P, Gellin G, Endean E and Fitzpatrick E: Effects of L-arginine on the proliferation of T lymphocyte subpopulations. JPEN J Parenter Enteral Nutr 25: 23-29, 2001.

139. de Jonge WJ, Kwikkers KL, te Velde AA, van Deventer SJ, Nolte MA, Mebius RE, Ruijter JM, Lamers MC and Lamers WH: Arginine deficiency affects early B cell maturation and lymphoid organ development in transgenic mice. J Clin Invest 110: 1539-1548, 2002

140. Manning J, Mitchell B, Appadurai DA, Shakya A, Pierce LJ, Wang H, Nganga V, Swanson PC, May JM, Tantin D, et al: Vitamin C promotes maturation of T-cells. Antioxid Redox Signal 19: 2054-2067, 2013.

141. Dahl $\mathrm{H}$ and Degré M: The effect of ascorbic acid on production of human interferon and the antiviral activity in vitro. Acta Pathol Microbiol Scand B 84B: B280-B284, 1976.

142. Huijskens MJAJ, Walczak M, Sarkar S, Atrafi F, Senden-Gijsbers BL, Tilanus MG, Bos GM, Wieten L and Germeraad WT: Ascorbic acid promotes proliferation of natural killer cell populations in culture systems applicable for natural killer cell therapy. Cytotherapy 17: 613-620, 2015.

143. Anderson R: Assessment of oral ascorbate in three children with chronic granulomatous disease and defective neutrophil motility over a 2-year period. Clin Exp Immunol 43: 180-188, 1981.

144. Patrone F, Dallegri F, Bonvini E, Minervini F and Sacchetti C: Effects of ascorbic acid on neutrophil function. Studies on normal and chronic granulomatous disease neutrophils. Acta Vitaminol Enzymol 4: 163-168, 1982. 
145. Moraes MP, de Los Santos T, Koster M, Turecek T, Wang H, Andreyev VG and Grubman MJ: Enhanced antiviral activity against foot-and-mouth disease virus by a combination of type I and II porcine interferons. J Virol 81: 7124-7135, 2007.

146.Peng T, Zhu J, Hwangbo Y, Corey L and Bumgarner RE: Independent and cooperative antiviral actions of beta interferon and gamma interferon against herpes simplex virus replication in primary human fibroblasts. J Virol 82: 1934-1945, 2008.

147.Bartee E, Mohamed MR, Lopez MC, Baker HV and McFadden G: The addition of tumor necrosis factor plus beta interferon induces a novel synergistic antiviral state against poxviruses in primary human fibroblasts. J Virol 83: 498-511, 2009.

148.Page C, Goicochea L, Matthews K, Zhang Y, Klover P, Holtzman MJ, Hennighausen L and Frieman M: Induction of alternatively activated macrophages enhances pathogenesis during severe acute respiratory syndrome coronavirus infection. J Virol 86: 13334-13349, 2012.

149.Block G, Jensen CD, Dalvi TB, Norkus EP, Hudes M, Crawford PB, Holland N, Fung EB, Schumacher L and Harmatz P: Vitamin C treatment reduces elevated C-reactive protein. Free Radic Biol Med 46: 70-77, 2009.

150.Kim WY, Jung JW, Choi JC, Shin JW and Kim JY: Subphenotypes in patients with septic shock receiving vitamin $\mathrm{C}$, hydrocortisone, and thiamine: A retrospective cohort analysis. Nutrients 11: 11, 2019.

151. Grahame Hardie D: Regulation of AMP-activated protein kinase by natural and synthetic activators. Acta Pharm Sin B 6: 1-19, 2016.

152. Pagé EL, Chan DA, Giaccia AJ, Levine $M$ and Richard DE: Hypoxia-inducible factor- $1 \alpha$ stabilization in nonhypoxic conditions: Role of oxidation and intracellular ascorbate depletion. Mol Biol Cell 19: 86-94, 2008.

153. Witte MB and Barbul A: Arginine physiology and its implication for wound healing. Wound Repair Regen 11: 419-423, 2003.

154.Padayatty SJ, Sun H, Wang Y, Riordan HD, Hewitt SM, Katz A, Wesley RA and Levine M: Vitamin C pharmacokinetics: Implications for oral and intravenous use. Ann Intern Med 140: 533-537, 2004.

155. Stancioiu F: Antiviral activity of L-arginine and extended-release Vitamin C. AASCIT J Health 3: 13-16, 2016.

156. Bertolini G, Iapichino G, Radrizzani D, Facchini R, Simini B, Bruzzone P, Zanforlin G and Tognoni G: Early enteral immunonutrition in patients with severe sepsis: Results of an interim analysis of a randomized multicentre clinical trial. Intensive Care Med 29: 834-840, 2003.

157. Heyland DK, Novak F, Drover JW, Jain M, Su X and Suchner U: Should immunonutrition become routine in critically ill patients? A systematic review of the evidence. JAMA 286: 944-953, 2001.

158. Rosenthal MD, Rosenthal C, Patel J, Jordan J, Go K and Frederick A Moore FA: Arginine in the critically ill: Can we finally push past the controversy? Int J Crit Care Emerg Med 2: $017,2016$.

159.Galbán C, Montejo JC, Mesejo A, Marco P, Celaya S, Sánchez-Segura JM,Farré Mand Bryg DJ: Animmune-enhancing enteral diet reduces mortality rate and episodes of bacteremia in septic intensive care unit patients. Crit Care Med 28: 643-648, 2000.
160. Luiking YC, Poeze $M$ and Deutz NE: Arginine infusion in patients with septic shock increases nitric oxide production without haemodynamic instability. Clin Sci (Lond) 128: 57-67, 2015.

161. Gough MS, Morgan MAM, Mack CM, Darling DC, Frasier LM, Doolin KP, Apostolakos MJ, Stewart JC, Graves BT, Arning E, et al: The ratio of arginine to dimethylarginines is reduced and predicts outcomes in patients with severe sepsis. Crit Care Med 39: 1351-1358, 2011.

162. Visser M, Davids M, Verberne HJ, Kok WE, Tepaske R, Cocchieri R, Kemper EM, Teerlink T, Jonker MA, Wisselink W, et al: Nutrition before, during, and after surgery increases the arginine:asymmetric dimethylarginine ratio and relates to improved myocardial glucose metabolism: a randomized controlled trial. Am J Clin Nutr 99: 1440-1449, 2014.

163. Visser M, Vermeulen MAR, Richir MC, Teerlink T, Houdijk AP, Kostense PJ, Wisselink W, de Mol BA, van Leeuwen PA and Oudemans-van Straaten HM: Imbalance of arginine and asymmetric dimethylarginine is associated with markers of circulatory failure, organ failure and mortality in shock patients. Br J Nutr 107: 1458-1465, 2012.

164. Arora TK, Malhotra AK, Ivatury R and Mangino MJ: L-arginine infusion during resuscitation for hemorrhagic shock: Impact and mechanism. J Trauma Acute Care Surg 72: 397-402, 2012.

165.Wu F, Wilson JX and Tyml K: Ascorbate protects against impaired arteriolar constriction in sepsis by inhibiting inducible nitric oxide synthase expression. Free Radic Biol Med 37: 1282-1289, 2004.

166. Wang Y, Lin H, Lin BW and Lin JD: Effects of different ascorbic acid doses on the mortality of critically ill patients: a meta-analysis. Ann Intensive Care 9: 58, 2019.

167. Fowler AA III, Truwit JD, Hite RD, Morris PE, DeWilde C, Priday A, Fisher B, Thacker LR II, Natarajan R, Brophy DF, et al: Effect of vitamin $\mathrm{C}$ infusion on organ failure and biomarkers of inflammation and vascular injury in patients with sepsis and severe acute respiratory failure: The CITRIS-ALI Randomized Clinical Trial. JAMA 322: 1261-1270, 2019.

168. Calina D, Docea AO, Petrakis D, Egorov AM,Ishmukhametov AA, Gabibov AG, Shtilman MI, Kostoff R, Carvalho F, Vinceti M, et al: Towards effective COVID-19 vaccines: Updates, perspectives and challenges (Review). Int J Mol Med 46: 3-16, 2020.

169. Chan MHM, Wong VWS, Wong CK, Chan PK, Chu CM, Hui DS, Suen MW, Sung JJ, Chung SS and Lam CW: Serum LD1 isoenzyme and blood lymphocyte subsets as prognostic indicators for severe acute respiratory syndrome. J Intern Med 255: 512-518, 2004.

170. Hicks CW, Wang D, Daya NR, Windham BG, Ballantyne CM, Matsushita K and Selvin E: Associations of cardiac, kidney, and diabetes biomarkers with peripheral neuropathy among older adults in the atherosclerosis risk in communities (ARIC) study. Clin Chem 66: 686-696, 2020.

This work is licensed under a Creative Commons Attribution-NonCommercial-NoDerivatives 4.0 International (CC BY-NC-ND 4.0) License. 